\title{
INDUSTRIALIZACIÓN MINERA, URBANIZACIÓN E INNOVACIÓN \\ EN LAS RELACIONES SOCIALES EN EL SUDOESTE DEL ALTIPLANO \\ BOliviano: El CASO de la COMPAÑía HuANChaca de Bolivia
}

$(1834-1930)^{1}$

\author{
Damir Galaz-Mandakovic ${ }^{2}$
}

\section{* Introducción}

Resumen

Se analiza el caso de la Compañía Huanchaca de Bolivia como prototipo de un proceso de instauración de una economía capitalista de enclave industrial en el sudoeste de Bolivia, centrando el análisis en la transición artesanal a la industrial y sus efectos tecnológicos, mecánicos y urbanos que resultaron gravitantes para procesos migratorios. Del mismo modo, se caracteriza este proceso de industrialización que trae aparejado enlaces asimétricos con los saberes tradicionales, estableciendo nuevas formas de control por parte del Estado y capitalistas mineros hacia los indígenas, estableciendo, de esta forma, nuevas relaciones sociales.

Palabras claves: industrialización - Compañía Huanchaca - enclave migraciones - altiplano - relaciones sociales.

\begin{abstract}
It is analyzed the case of the Huanchaca Company of Bolivia as a prototype of an implementation process based on a capitalist economy of industrial enclave in southwestern Bolivia. Focusing the analysis on the artisanal transition to industrial and technological effects, mechanical and urban gravitating for the migration processes. Similarly, this process is characterized by bringing asymmetric links with traditional

knowledge, establishing new forms of control both by the state and capitalists miners towards indigenous. Therefore new social relationships are established.

Key words: industrialization - Huanchaca Company - enclave - migration - Altiplano - social relations.
\end{abstract}

Recibido: octubre 2015. Aceptado: enero 2016.
La Compañía Minera Huanchaca trazó una inscripción capitalista y colonialista que transformó significativamente el sudoeste boliviano, impactando a través de dinámicas tecnológicas, viales, sociales y económicas; compuso nuevas formas de relación entre empresarios, indígenas, el Estado y un territorio revalorizado en un contexto mercantil transfronterizo.

Las referencias a Huanchaca son múltiples; sin embargo, consideramos que no se han detallado, o caracterizado, ni interpretado algunos de sus procesos, referidos a la conformación de un revolucionario enclave capitalista minero, escaseando a su vez los detalles sobre los procesos de mecanización y procesos de urbanización - concretamente sobre Uyuni-, y también sobre las discontinuidades y relaciones colonialistas entre nativos y empresariado.

En base a lo dicho, nos preguntamos lo siguiente: ¿Cuáles fueron los procesos que instauró la compañía Huanchaca en su ímpetu de industrialización capitalista minera, y qué tipo de discontinuidades y relaciones sociales se evidenciaron?

En ese sentido, daremos cuenta de los orígenes de la compañía Huanchaca en 1834 hasta su tránsito a la

1 Los resultados de investigación de este artículo son parte del proyecto Fondecyt $\mathrm{N}^{\circ} 11110487$ (2011-2014) "Caminos y biografías, la puna sur andina desde sus márgenes industriales (1920-1980)", proyecto dirigido por Dr. Nicolás Richard.

2 Programa de Doctorado en Historia de Université Rennes 2. Ecole Européenne de Bretagne y Programa de Doctorado en Antropología Universidad Católica del Norte. Calle R.P. Gustavo Le Paige N³80, San Pedro de Atacama, Región de Antofagasta, CHILE. Email: damirgalaz@gmail.com

3 P. ej.: Latcham 1926; Arce 1930; Espinoza 1958; Lora 1967; Ferrer 1975; Zavaleta 1977, 1983; Soto 1978; Escobar 1984; Antezana 1985; Kindgard 1987; Lazarte 1987; Platt, 1987, 2014; Rutledge 1987; Barros 1995; Querejazu 1996; Finn 1998; Ahumada 1999; Sanhueza 2001, 2011; Tapia 2001; Recabarren 2002; Montero 2004; López Nina 2005; Mesa et al. 2007; González Pizarro 2008, 2010, 2011, 2012; González Miranda 2009; Ardiles 2010; Gómez 2010; Mamani, 2010; Morales 2010; López Pérez 2011; Serrano 2011; Chungara s/f; Field s/f. 
industrialización y conformación de un relevante consorcio que provoca importantes procesos tecnológicos, mecánicos, sociales y urbanos hasta 1930.

Una vez que la compañía irrumpe con el ferrocarril, analizamos esta verdadera revolución mecánica y el proceso de urbanización que trae aparejado, incorporando procesos migratorios, estratificación y representación. Finalmente, analizaremos el devenir de la compañía, su relación con las discontinuidades arrieras y el fuerte proceso de aduanización y control que se ejerció para reforzar las fronteras e intervenir ante las agencias de la población autóctona.

Caracterizaremos y analizaremos las relaciones heterogéneas o asimétricas que se establecen entre indígenas y capitalistas, dando muestra también de cómo un Estado es subsumido en su gestión, políticas y ordenanzas, para integrar y satisfacer los intereses de un importante enclave económico (Conning et al. 2009) en territorio de indígena.

\section{Origen de la compañía Huanchaca}

Los orígenes de la Compañía Minera Huanchaca nos remiten al año 1834, su precursor fue el minero boliviano Mariano Ramírez (Concha y Toro 1872; Subieta 1928). Se constituyó como empresa netamente boliviana (Espinoza 2010), dedicada a la explotación de la mina de Pulacayo ${ }^{4}$, incluyendo la instalación de un ingenio para el tratamiento de los metales. Cabe indicar que las vetas de Pulacayo fueron trabajadas desde épocas prehispánicas (Lechtman et al. 2010), acumulándose desde entonces voluminosos desmontes (Concha y Toro 1872; DGEEG 1912).

4 El cerro minero de Pulacayo está ubicado entre la cordillera de los Chichas y las faldas de la cordillera de los Frailes, rodeando por los cerros Paisano y el Pupusani el departamento de Potosí. Sus coordenadas son $20^{\circ} 23^{\prime} 26^{\prime \prime} \mathrm{S}, 66^{\circ} 41^{\prime} 53^{\prime \prime} \mathrm{W}$.

5 Cerro ubicado en el departamento de Potosí, provincia Antonio Quijarro, en el municipio de Tomave. $20^{\circ} 10^{\prime} 60^{\prime \prime} \mathrm{S} 66^{\circ} 40^{\prime} \mathrm{O}^{\prime \prime} \mathrm{W}$. Posee una distancia de cuatro leguas de Pulacayo (Concha y Toro 1872).

6 Las actividades políticas de Arce, paralelas a sus actividades empresariales, lo llevan ser elegido presidente de Bolivia para el período 1888-1892.
Eujenio Bobiller (1897) testifica que el laboreo de las vetas fue considerable, y sus afloramientos muy raros y abundantes en minerales de fácil beneficio. Estas minas fueron abandonadas por varios motivos y en distintos períodos por "el alzamiento de los indios que mataban a sus dueños i destruían las obras existentes" (Concha y Toro 1872: 4). Posteriormente, fueron cesadas en períodos de las guerras de la Independencia (Subieta 1928). Desde entonces quedaron completamente abandonadas, hasta que en la década de 1830 "fueron sacadas del olvido mediante el enérgico y constante trabajo de un minero boliviano, que fundó la realización de sus sueños de fortuna, en la continuación de los primitivos y tortuosos laboreos de esta mina" (Bobiller 1897: 7).

Mariano Ramírez era un conocedor de la mayor parte de los minerales de la árida región de la altiplanicie y trabajaba, con la ayuda de indígenas, las vetas de plata en el cerro de Cosuño5 (Concha y Toro 1872; Bobiller 1897; DGEEG 1912). Esos mismos indígenas proporcionaron los datos sobre la existencia de las vetas argentíferas de Pulacayo en 1834 (Wright 1907).

Desde ese redescubrimiento, Pulacayo se revalorizó. Ramírez abandonó todos sus trabajos emprendidos en Cosuño para explotar Pulacayo, aun contando con escasos recursos. Los indígenas facilitaron el acceso a las huellas de las antiguas labores en la zona y prontamente se constituyó el socavón San León de Pulacayo, consiguiendo dar con la veta principal a 800 metros de profundidad (Concha y Toro 1872; MDIAJH 1876; Bobiller 1897; Wright 1907; DGEEG 1912).

\section{La renovación empresarial}

Para Ramírez, los resultados no coincidían con las proyecciones. Por ello, en el año 1850 se integró Aniceto Arce 6 para aportar capital y administrar la compañía, desplegando a la vez un trabajo de difusión sobre el proyecto minero con el objetivo de atraer nuevos socios (Serrano 2004).

En el año 1856, el directorio quedó integrado por Avelino Aramayo, Aniceto Arce y Gregorio Pacheco (MDIAJH 1876; DGEEG 1912). La explotación de las minas de Pulacayo comenzó a generar pingües ganancias, permitiendo el apogeo del consorcio entrando la década de 1870. 
Este proceso de esplendor permitió una reestructuración de la compañía en 1872 (ECHB 1873), significando la introducción de tecnologías y la incorporación de un mayor contingente laboral: en 1877 , ya trabajaban para el consorcio 1567 obreros y cerca de 10000 indios para transporte y trabajos forzados (Mesa et al. 2007). En esa escena, los indígenas fueron distribuidos, según sus capacidades, en distintos tipos de trabajos asalariados, ejerciendo de este modo la combinación entre lo tradicional y lo capitalista. Por ejemplo, los barreteros ganaban seis a ocho reales por día; los pongos, ocho reales; los ponguillos, cinco reales; los apires, cuatro reales, y los chivatos (muchachos), dos a tres reales. Las palliris ${ }^{7}$ también ganaban dos a tres y medio reales.

Además de la asalarización, se ejerció una forma de contratación de indígenas destinados al trabajo de molienda en Huanchaca, contrataciones que se concebían directamente, desde 1838, con los curacas indígenas de la quebrada del río Blanco en la provincia de Chichas, a 25 leguas de distancia (Platt 2014). Según el contrato, los curacas debían poner 24 tributarios cada tres semanas para trabajar como cedasiris ${ }^{8}$ y mortiris ${ }^{9}$. De esta forma, se pagaban dos reales a cada autoridad indígena, y dos reales a cada peón por su venida (Platt 2014).

Se adicionó personal capacitado en aspectos técnicos y administrativos, se inició un proceso de modernización, tanto en los socavones como en los ingenios. Se introdujeron las primeras máquinas a vapor y se realizaron mejoras en la recuperación metalúrgica. Igualmente, se amplió su capacidad mejorando las obras de captación de aguas. Se optimizó el transporte de minerales al interior de las minas con rieles y tracción a sangre, a través de la construcción de caminos secundarios (Concha y Toro 1872; Bobiller 1897; Wright 1907; DGEEG 1912; Arce 1930). En el decir de Schumpeter (1978), el carácter de empresa se generó con la introducción de "innovaciones radicales", con la capacidad e iniciativa para proponer y realizar "nuevas combinaciones de medios de producción".

Los procesos de liberalización de la economía boliviana, específicamente en el año 1872 con la suspensión del monopolio de la compra de minerales de plata, permitió un apogeo minero significativo, al menos en la área argentífera (Mesa et al. 2007). Al año siguiente, el pago de minerales dejó de ser en moneda feble ${ }^{10}$, permitiendo la conexión en mayor escala de la minería boliviana con el capitalismo mercantil (Velázquez 1905; Deustua 2004).

La reestructuración de 1873 permitió la obtención de un capital de B/6.000.000 (Bobiller 1897), gracias a la integración de capitalistas chilenos e ingleses ${ }^{11}$, permitiendo que se estableciera el domicilio de la compañía en Valparaíso (ECHB 1873). El proyecto resultó exitoso con el devenir de los años. Por ejemplo, en el año 1878 la compañía llegó a obtener una utilidad líquida de cerca de B/1.000.000 repartiendo a sus accionistas B/840.000 en dividendos ${ }^{12}$ (Bobiller 1897).

La reestructuración facilitó un proceso de industrialización que indujo a una mayor visibilidad de la compañía a través de sus ventajas competitivas: "Pulacayo famoso como la segunda comarca argentífera del mundo, correspondiendo el primer puesto á Broken Hill, de Australia" (Wright 1907:330). O como dijo un entusiasmado André Bellessort: "los minerales de plata provenientes de Pulacayo, la más rica mina de plata no solamente de Bolivia, sino que del mundo entero" (Bellessort 1897: 84).

Entre los años 1875 y 1880 , por el auge de las minas de Pulacayo, el sector comenzó a experimentar una mayor gravitación, amplificándose el pequeño poblado (Wright

7 Palliris viene del quechua "pa-llay": juntar. Eran las mujeres que separaban las piedras con mineral beneficiable en las afueras de las minas y también en los desmontes.

8 Cernían el metal triturado para producir una fina harina mineral.

9 Cuidaban las almadanetas de los morterados, suministrando nuevas piedras minerales para ser trituradas.

10 La llamada moneda feble buscó disminuir el flujo de monedas de plata hacia el exterior del país. Además de mitigar la escasez de plata menuda que se sentía en el mercado interno. Las utilidades que resultaron de esta amonedación se destinaron al establecimiento de un fondo para fomentar la explotación de oro en el país. Esta política monetaria rigió desde el 10 de octubre de 1829 hasta 1873. Ver: Santibáñez, J. 1872. Amortización de la moneda feble boliviana. Impr. del Siglo, Bolivia.

11 El primer consejo quedó compuesto por Aniceto Arce, Ernesto Decombe, Melchor Concha y Toro, Herman Fischer, Joaquín Dorado, Joaquín Rigan, como propietarios; como suplentes, Juan Wheelwrigth, H. O. Bourchier y Eduardo Squire (ECHB 1873).

12 B/es igual a "pesos bolivianos". 
1907; Velásquez 1912). Aumentaron, a su vez, las empresas carretoneras de transporte de plata de la compañía al puerto de Cobija (Risopatrón 1910).

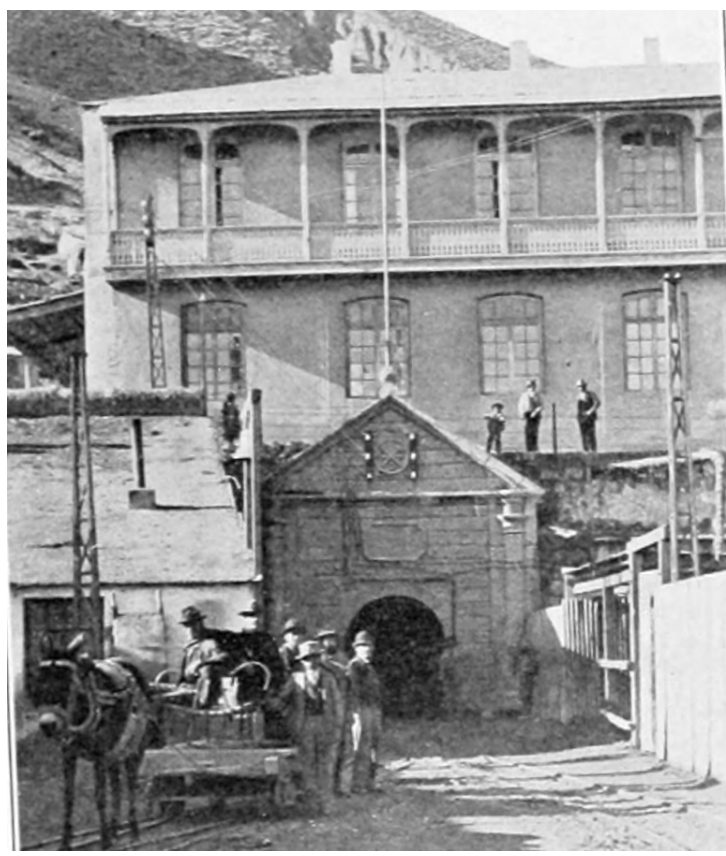

Figura 1. Socavón San León de Pulacayo, 1905. Archivo (C) Juan Colque.

\section{Enclave y gravitación}

El proceso de industrialización configuró a Pulacayo como lugar de atracción migratoria, dinamizando la producción agrícola de poblados aledaños, induciendo a que se transformaran en torno a una relación satelital. Los latifundios de Cochabamba, por ejemplo, proporcionaban granos, frutas, harina, legumbres y hortalizas. La ciudad de La Paz proveía tocuyos y otros tejidos, además de cerveza y cigarrillos, este último proveniente también de la zona de Chuquisaca; la ciudad de Potosí suministraba la leña; Oruro, la quinua, velas de cebo y parafina, y la ciudad de Tarija, las carnes y charqui (Flores y Martínez 2009).

Las actividades mineras de la compañía Huanchaca ejercieron una gravitación relevante al constituirse como centro de consumo, circulación monetaria y desarrollo comercial por excelencia (Flores y Martínez 2009). La población en Pulacayo, despuntado el siglo XX, superaba los 7000 habitantes, en su mayoría dependientes de las actividades mineras $^{13}$. (Ver Figura 1 y Figura 2).

13 Cifra en base a la Edición facsimilary estudios del Censo General de la Población de la República de Bolivia según el empadronamiento de 1ro. de septiembre de 1900 (Oficina Nacional de Inmigración, Estadística y Propaganda Geográfica de Bolivia, 1902).

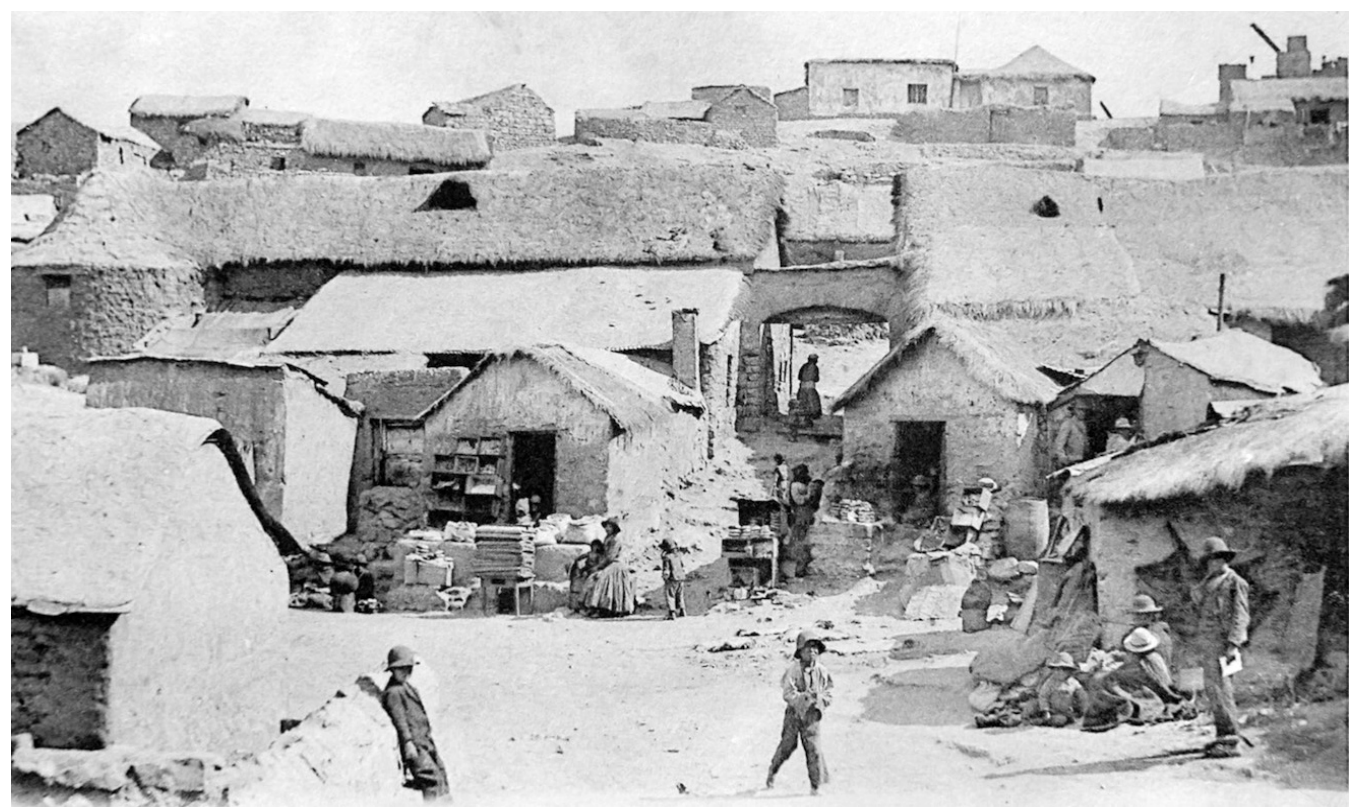

Figura 2. Comercio en los barrios de los mineros de Pulacayo, 1905. Archivo (C) Juan Colque. 
"Todo en la ciudad pertenece á la Compañía Huanchaca y ninguno puede vivir en la comunidad sin permiso de ella. Todos los empleados de la Municipalidad son nombrados por la Compañía y todas las instituciones están bajo su gobierno y vigilancia directa. Hay algunas iglesias, escuelas y hospitales y la población tiene un buen teatro. Es un pueblo minero característico, construido en forma de anfiteatro en el declive del cerro y las calles escarpadasy estrechas..." (Wright 1907:330).

Sin duda, en el comentario de Wright, es interesante la descripción del poder que va adquiriendo la empresa, la cual moldeó al poblado y lo estructuró en base a sus propios intereses, estableciendo relaciones capitalistas entre los nativos y la compañía. La tendencia a una colonización queda explicitada en conjunto a una estructura de enclave económico (Ardenti y Vrain 1999; Zapata 2002; Conning et al. 2009). Es decir, existe una compañía que supera a la acción e inversión del Estado en dicha región, existiendo un alto control externo en las actividades productivas (Hirschman 1973). Ese control externo tiende a colonizar a los actores locales, especialmente al mundo indígena. Tal como lo señala José Deustua, "la minería jugó un papel desarticulador de las economías nacionales en vez de integrarlas a un proceso nacional" (2004: 95).

Este proceso de industrialización y conformación de enclave funcionó como una apuesta dinámica o integradora, tanto a nivel local como nacional (Levin 1960; Cademartori 2010). Es una zona que ejerce una gravitación, pero desde una relación asimétrica entre los grupos locales y los foráneos. Su relación con el resto de la economía fue, principalmente, a través de su vinculación con el mercado mundial. En las economías regionales se generan economías duales en las cuales coexisten paralelamente el centro del enclave, que representa a un sector capitalista tecnológicamente avanzado, y su periferia, un sector tradicional (Ardenti y Vrain 1999; Zapata 2002; Cademartori 2010). Ambos sectores se enlazan desde una asimetría.

Para comprender un poco más esta dinámica transformadora, podemos ver que en el año 1885, con la "lei del 23 de noviembre", el pueblo de Huanchaca fue declarado como "capital de la provincia de Porco: el pueblo de Pulacayo es vice-cantón dependiente de la capital”, por orden de un accionista en Huanchaca y presidente de Bolivia a su vez: Gregorio Pacheco (1884-1888). Se decretaba que en el pueblo de Huanchaca "Residirán las autoridades políticas, municipales y judiciales. Se mantendrá en dicha capital, ú otro punto de la provincia, un resguardo militar. El pueblo Pulacayo, es vice-cantón dependiente de la capital y tendrá correjidor, alcaldes parroquiales y ajentes cantonales." (AGOB, "lei 23 de noviembre 1885").

Otra de las medidas tuvo alusión directa a la potestad del poder ejecutivo nacional para expropiar, “...conforme á las leyes, los edificios que se necesitáre en Huanchaca y en Pulacayo para instalar las oficinas respectivas." (AGOB, "lei 23 de noviembre 1885"). ${ }^{14}$

Aunque en términos jurídicos, el Estado realizaba una intervención, la factualidad indicaba otra realidad, tal como lo apuntaba Wright en 1907, en un matrimonio ejercido entre políticos, los administradores del Estado y empresa. ${ }^{15}$ En la lógica de un enclave económico, el Estado actúa subsumido dentro de una relación capitalista de producción (Ardenti y Vrain 1999; Zapata 2002).

Este proceso de industrialización conllevó el mejoramiento de los establecimientos de amalgamación y tratamiento de los metales sulfurosos. "Para el acarreo de los minerales de Pulacayo al injenio de Huanchaca, cuenta la sociedad con cerca de 300 mulas y 25 carretas y con el material completo para poder aumentar las últimas hasta el número de 50" (Concha y Toro 1872: 24).

14 El 18 de agosto de 1912, se ordenó el levantamiento al rango de cantones a los asientos mineros Huanchaca y Pulacayo de la provincia Porco, departamento de Potosí.

15 Cademartori, en la teorización de las economías de enclave, apunta:

"El Estado delega tareas en las empresas extranjeras con lo cual el Estado se transforma en un socio extranjero (...) La población local es pobre en comparación a la riqueza de las empresas extranjeras y esta pobreza puede inducirle a conformarse con pequeñas ventajas de corto plazo. A la elite que controla el Estado nacional le interesa mantener al enclave para obtener divisas luego debe luchar con los actores locales para captar los excedentes que quedan en el país. Para ello basta que un reducido número de personas pero con gran poder dentro del enclave se beneficie de la presencia de las empresas extranjeras" (Cademartori 2010: 22). 
Aún realizados los mayores esfuerzos en la gestión, a pesar de la relevancia que iba tomando la mina, no se obtuvieron los resultados esperados por el factor del traslado del mineral hacia el litoral: una gran distancia que encarecía el transporte y dilataba los plazos (Bobiller 1897; Wright 1907; Arce 1930; Ahumada 2002).

Surgida esa dificultad, enmarcada en la lejanía con la costa, los establecimientos de amalgamación de Huanchaca no podían beneficiar con provecho sino metales de ley superior a 50 marcos por cajón ${ }^{16}$, quedando, por lo tanto, una gran cantidad de minerales de leyes inferiores en los desmontes, en las llamadas minacanchas. La compañía no podía aprovechar, debido a que el beneficio en los establecimientos citados era muy costoso. Por otra parte, el combustible necesario para dar movimiento a las máquinas de la mina para las necesidades del beneficio, que eran la yareta y la leña suministradas por las poblaciones indígenas, se hicieron cada vez más escasas. Ante esa insuficiencia, tuvo que ser forzosamente reemplazado por el carbón de piedra, que tenía que llevarse desde la costa en carretas, cuyo alto costo alcanzaba, en los primeros tiempos, hasta 150 bolivianos por tonelada (Concha y Toro 1872; Bobiller 1897).

Los minerales ricos explotados, de ley superior a 150 marcos por cajón, eran tratados en el ingenio de Huanchaca, constituyendo la principal fuente de entrada para la compañía. Luego eran trasladados a la costa: para este servicio se contaba con una gran cantidad de carretas propias, que hacían el largo recorrido desde la mina hasta Cobija, llevando minerales y trayendo de retorno maquinarias, carbón, materiales y algunas mercaderías para los campamentos (Concha y Toro 1872; Bellesort 1897; Bobiller 1897).

"Es interesante visitar un ingenio y seguir los varios métodos porque son tratados los minerales antes de salir del último procedimiento en lucientes parras de plata ó estaño, listas para ser cargadas sobre mulas, llamas y asnos (...) Los grandes sacos que contienen mineral para ser embarcado en condiciones ordinarias como sale de la mina, son transportados en mulas; pero los trozos cuadrados, que pesan veinticinco libras, son generalmente llevados por llamas" (Wright 1907: 334).

16 En Pulacayo, el cajón de mineral constaba de “50 quínteles" de 46 kilos cada uno (Bobiller 1897).
El traslado era sumamente costoso por las grandes distancias que había que recorrer, además de atravesar caminos que en la altiplanicie se hacían casi intransitables en la época de lluvias estivales. Todo este proceso de transportes recargaba considerablemente los gastos de la compañía Huanchaca, paralizando el desarrollo de los trabajos de la mina, cuyas maquinarias de explotación y beneficio tuvo que reducirse a las dimensiones de un trasporte de esta naturaleza (Concha y Toro 1872; Bobiller 1897).

Bobiller apuntó que, por ejemplo, en el año 1887 se exportaron alrededor de 89000 quintales de minerales, costando este trasporte la enorme suma de $\mathrm{B} / 800.000$, lo que significaba cerca de 5/10 por quintal; si a esta cifra se agrega lo pagado por flete de materiales y mercaderías internados a Pulacayo en el mismo año, se ve lo costoso del proceso y la urgencia de recurrir a un sistema que generara una gran economía para la empresa a través de un sistema de transporte ferroviario.

En el período previo a la guerra del Pacífico, el tráfico de carretas con los minerales hacia el puerto de Cobija se realizaba en mulas de carga y por una ruta no formalizada. Esa ruta arriera y de postas coloniales, y luego boliviana, abarcaba: Pulacayo, Amachuma, Púquios, Río Grande, Alota, Viscachillas, Tapalquilcha, Ascotán, Polapi, Santa Bárbara, Incahuasi, Chiu-Chiu, Calama, Miscanti, Colupo, Gatico y Cobija. Se consideraba que existía una longitud de 520 kilómetros (Bobiller 1897; Risopatrón 1910).

Para este viaje de 18 días (Bobiller 1897; Wright 1907; Risopatrón 1910; Arce 1930), los indígenas que trabajan en el transporte tenían la misión de conseguir forraje para las mulas, el cual era obtenido entre Huanchaca y el sector de Ascotán a partir de la cebada en rama que producen algunos lugares de la altiplanicie, con la cual se realizaban grandes depósitos en las distintas postas del camino. Entre Ascotán y Cobija, se recurría al pasto que producían las llamadas "vegas de Calama". En ese sentido, los saberes autóctonos y el rol de los baqueanos fueron fundamentales para poder concretar la exteriorización de la producción minera (Bobiller 1897; Risopatrón 1910).

En el contexto de la guerra del Pacífico, Huanchaca sufrió 
el bloqueo de tráficos desde el altiplano a la costa, por ello vio la necesidad de buscar una salida por el Atlántico, generando una nueva ruta por el puerto argentino de Rosario. No obstante, esta ruta resultaba más costosa en comparación con la ruta hacia el puerto de Cobija, aunque los recursos en forrajes con que se contaba en el trayecto a Rosario eran más abundantes y baratos; la mayor distancia que había que recorrer hizo que el costo de transporte por quintal fuese más o menos el mismo en ambos casos, teniendo este último la desventaja del mayor tiempo empleado en cada viaje (Bobiller 1897).

Finiquitada la guerra del Pacífico, el retiro de las guarniciones militares favoreció la reactivación de tráficos recién en el año 1885 (Sanhueza 2012).

\section{Cuerpo y trabajo indígena para Huanchaca}

La composición de empleados en Huanchaca puede ser entendida como una nueva composición proletaria, relacionada con su carácter de artesanía, perteneciente a una empresa. Un grupo de indígenas concentrados masivamente, quienes desplegaron habilidades productivas desde una tradición, disponiendo del cuerpo para el trabajo.

Desde esta condición proletaria comenzaron a convivir fuertes vínculos con la estructura productiva, caracterizada por la ruptura tecnológica que imprime Huanchaca en el altiplano. Pero, a pesar de la gran renovación tecnológica que va a experimentar la minería, cerca del $35 \%$ de la producción de empresas modernas como Huanchaca iba a depender de ciertas labores manuales, como la de las palliris (Rodríguez 2014) que, como en esta empresa, llegaron a constituir alrededor del $43 \%$ de la fuerza laboral de Bolivia (Mitre 1981). (Figura 3).

En base al informe de Sisson (1905), se detalla que las mulas, las llamas e indios, en una violenta sinonimia, "eran los métodos de transporte más conveniente". En los detalles dados en estas transportaciones, se indicó: "Una mula podía transportar entre 200 o 300 libras de carga a razón de 12 o 15 leguas por un día; un burro transportaba la mitad cubriendo una jornada diaria de 5 a 8 leguas. Las llamas eran más frágiles: 50 a 100 libras y no más de 4 leguas." (Sisson 1905: 144). Por ello, los arrieros también eran llamados como cumuris $^{17}$ (Serrano 2004).
En el "análisis de los indios", en una curiosa comparación técnica con los animales, el informe consignó: "un indio lleva por regla general de 50 a 100 libras en la espalda, pero por cortas distancias a veces lleva hasta 300 libras, cuando está ligeramente cargado puede andar de 6 a 8 leguas por día. Pero había igual escasez de indios que de llamas porque eran empleados principalmente en el trabajo de minas y con excepción de pocos distritos no se le usa para el transporte de mercaderías" (Sisson 1905: 144).

Además de la asalarización de las labores indígenas y la reutilización de saberes mineros ${ }^{18}$, permitió la continuidad de saberes tradicionales, por ejemplo, las palliris.

“(..) un millar por lo menos, son mujeres ocupadas en escoger los minerales y distribuirlos de acuerdo con su calidad y propiedades. Es admirable lo experta que son estas mujeres en sus tareas y con qué aparente indiferencia lanzan los pedazos de mineral en un montón ó en otro, hablando, murmurando y pareciendo que no tienen la más ligera idea de la clase de material que manejan. Sin embargo, nunca se equivocan y el administrador de la mina dice que son más rápidas que un químico de experiencia en averiguar las diferentes clases de minerales." (Wright 1907:334).

Esta práctica es igualmente reportada por Concha y Toro en 1872 , mencionando que todo el mineral que se extraía en el socavón se chancaba y se pallaba. "Se clasificaba gracias al trabajo de las mujeres. De este modo se formaban tres clases principales de minerales: $1^{\circ}$ Guía; $2^{\circ}$ Galenas arjentiferas; $3^{\circ}$ Brosa" (Concha y Toro 1872: 16).

Archivos documentales permiten acceder a un caso judicial para conocer y develar la precariedad en la salud de mujeres por efecto de estos laboreos de palleo, consignado en un sumario criminal instruido por motivo de la muerte de Andrea Suárez, acaecida en San Pedro de Atacama el 15 de abril del año 1898 .

17 Cumuris es una palabra que deriva del quechua y hace mención a kúmu: agachado o agobiado, y del sufijo iri: acción o calidad, es decir, agobiados por el peso (Abecia 1988; Serrano 2004).

18 Sobre el trabajo de los indígenas y los mecanismos de reclutamiento en Lípez, ver: Gil Montero, R. 2014. Mecanismos de reclutamiento indígena en la minería de plata: Lípez (sur de la actual Bolivia), siglo XVII. América Latina en la historia económica $21(1): 5-30$. 


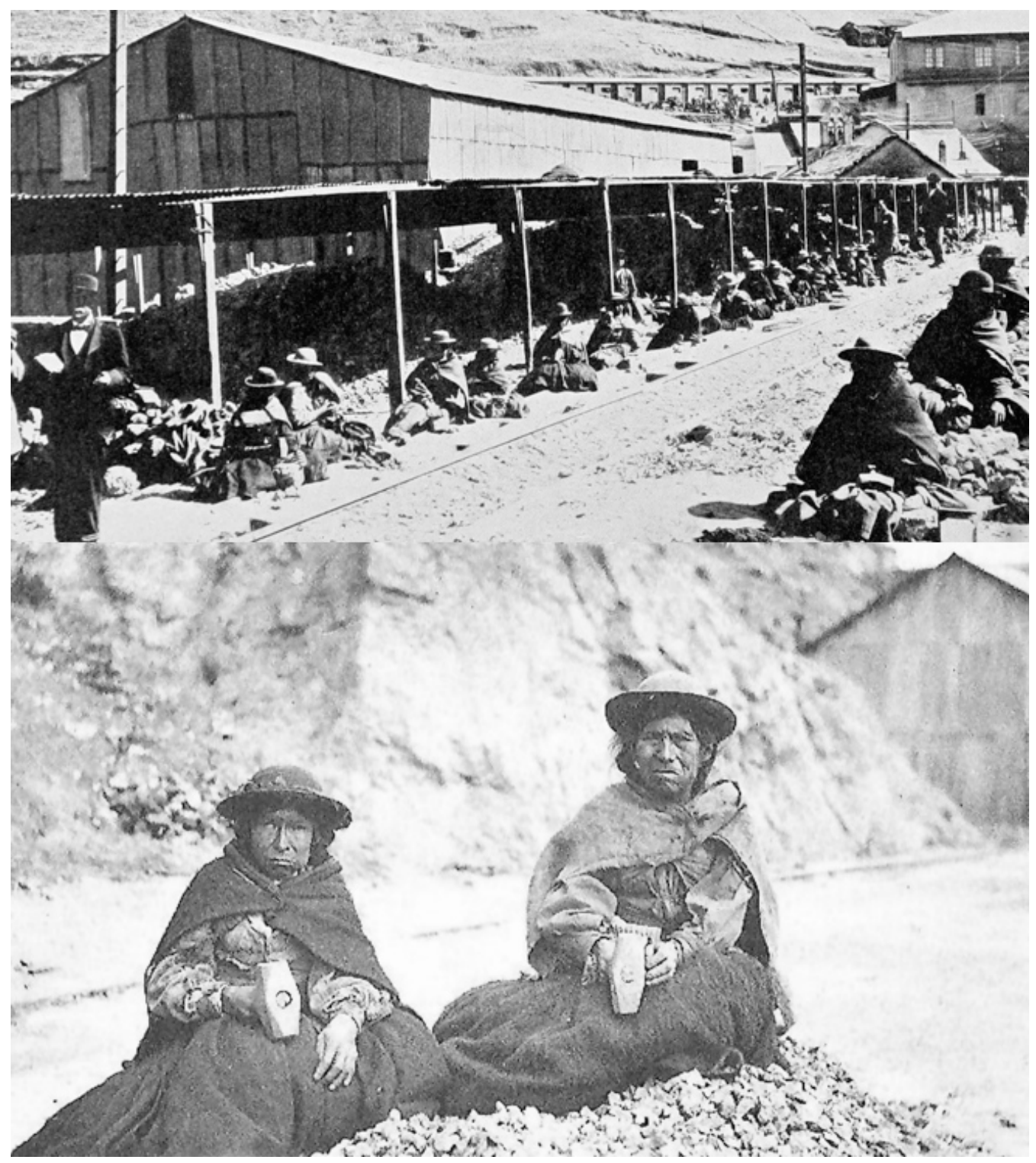

Figura 3. Grupo de palliris en la molienda y separación de piedras vigiladas por los hombres de traje negro, 1905. Archivo (C) Juan Colque.

Cabe indicar que la muerte es caracterizada como "sorpresiva". Lo interesante de este caso es la declaración de los cercanos a la occisa, entre ellos José Santos Puca, de 35 años, nacido en Susques, quien menciona:

"Había conocido a Andrea Suárez en Calama. Ella es de Cochabamba, luego ambos se trasladaron a San Pedro de Atacama. 'Donde vivimos trabajando al jornal en faenas de labranza', ambos le trabajaban a Félix Cruz. El acusado afirma que ella murió de pulmonía (...) y ella siempre se quejaba que dolía la espalda y el pescuezo' (...) agrega que la finada trabajó en el mineral de
Huanchaca de Bolivia y que desde entonces sentía mal los pulmones" (AJA, legajo $800 \mathrm{~N}^{\circ} 111898$ ).

Podemos inferir que las dolencias pulmonares y "en el pescuezo" pueden ser atribuidas a la silicosis, ${ }^{19}$ resul-

19 La sílice es un cristal, componente principal de la arena, que se presenta naturalmente y se encuentra en la mayoría de los lechos rocosos y forma polvo durante el trabajo con minería, la explotación de canteras, la construcción de túneles y al trabajar con muchos minerales metálicos. 
tante de una exposición a cantidades generosas de sílice durante corto tiempo. Los pulmones se inflaman y tienden a llenarse de líquido, causando una dificultad respiratoria grave y bajos niveles de oxígeno en la sangre. Según Platt, en la etapa preindustrial, Mariano Ramírez ya notaba problemas en la salud de los indígenas y peones de molienda, "por el polbo del metal, por el Arsénico, y Antimonios que contiene el metal negrillo; pero es tal la virtud del agua de ese río, que luego que llegan a sus casas, y toman la chicha y agua, son purgados" (Ramírez, citado por Platt 2014).

El proceso de industrialización en el cual participan los indígenas tiene también relación con las vulnerabilidades que se fundan en el traslado de metales hacia la costa. Podemos visibilizar el caso de un arriero asaltado: "En subdelegación ambulante de la línea férrea de Calama a la frontera, el 1 de marzo 1886, el subdelegado se traslada al campamento de Cere para investigar alevoso atentado, siendo víctima Nicolás Choque, arriero que conducía metales desde Huanchaca a Calama a quién, además de herirlo, le quitaron dos de los sacos con metales, de los que era portador" (AJA, legajo $835 \mathrm{~N}^{\circ} 13$ ).

En las postas durante el trayecto desde el mineral a la costa, se acredita la venta de alcohol, dando pie a pleitos y conflictos y, también, a quitadas de mineral:

"Se señala que por estar establecido en la posta de Cere, Alejandro Quevedo y Roberto Rojas con un negocio de licores, se produjo una pelea entre los que habian, siendo herido cinco de ellos. Al día siguiente pasaba por ahí Nicolás Choque con una tropa que conducía metales desde Huanchaca cuando fue asaltado por los que alli se encontraban, esto fue en presencia de Mauricio Ormazábal (alias el mono), Sotero Campos, José Segundo Araya, Ramón Díaz y otros. Todos ellos y los dueños del negocio, se encuentran residiendo en Calama" (AJA, legajo $835 \mathrm{~N}^{\circ}{ }_{13}$ ).

En la declaración de la víctima, asevera que, "venía del trapiche con 68 sacos de metal de plata perteneciente a la compañía Huanchaca. En la aguada de Cere llegaron 10 individuos..." (AJA, legajo $835 \mathrm{~N}^{\circ}$ 13).

Estos interesantes datos, que nos hablan de la modalidad de transportes, de sus volúmenes y de las vulnerabilidades a las que estaban expuestos los transportistas, relatan, además, la relación liminar entre aguadas y posadas.
No obstante, podemos indicar que la instauración de este sistema arriero en Huanchaca llevó consigo nuevas formas de control de la identidad, estrechamente en la lógica de prácticas anatomopolíticas (Foucault 2000).

"Es particularmente entretenido ver retratar á los arrieros antes de salir con sus cargas. Uno después de otro son colocados frente á la cámara, con los números á la vista, de modo que no pueda haber equivocación" (Wright 1907:334).

La introducción de una cámara fotográfica constituye una novedad, un dispositivo, una tecnología que lleva de la mano la reproducción de una imagen corporal que se desea controlar. "El objeto de esto es capacitar á la compañía para identificar al arriero en caso de que se esconda ó abandone su carga. No hay peligro de que se robe la plata ó los trozos de estaño, pero hay siempre la posibilidad de que pueda cansarse de su tarea, antes de llegar á su destino, y deje la carga, mulas y llamas en el camino y busque un empleo que le agrade más" (Wright 1907: 334).

El objetivo estaba claro: "Por medio del retrato se puede seguir fácilmente la huella del delincuente" (Wright 1907: 334). El nativo comenzó a ser visto con potencia delincuencial, al expresar su posibilidad de deserción y robo. Culpabilización que cierra la posibilidad del asalto, situación expuesta que ya hemos retratado. "Del modo que sea, esto sirve á los propietarios de excelente medio para estar informados de los pasos y conducta de estos indios. Los delincuentes proporcionan una especie de 'colección de identificación', que sirve de salvaguardia á los establecimientos mineros" (Wright 1907: 334).

De este modo, surge un archivo de cuerpos retratados en el altiplano industrializado. Un archivo de indios vistos con potencia de delito, con potencia "de traición", el indio como sujeto de una "deseconomía". El cuerpo del indígena en Pulacayo comenzó un proceso escritural y prontuarial en una escena capitalizada.

Todo este proceso fotográfico para agenciar "cuerpos docilizados" nos remite a técnicas de control anatomopolíticas, en el sentido de expresar, a través de las fotografías, la identificación somática y el control de la ruta de los arrieros como tecnología individualizante y fragmentaria por parte de los empresarios mineros. El traslado de minerales por parte de estos arrieros estaba basado 
en la disciplina como instrumento de control del cuerpo social. Fotografiarlos, y registrarlos en formularios descriptivos de sus cuerpos, nos remiten a la vigilancia, al control, a la intensificación del rendimiento, multiplicación de capacidades, el trazado del desplazamiento para obtener la utilidad. En ese itinerario "la vigilancia pasa a ser un operador económico decisivo en la medida en que es a la vez pieza interna del aparato de producción" (Foucault 1996: 180).

No obstante Wright, a pesar de estos procedimientos identificatorios que constituyen una nueva práctica en el altiplano, describe la "sumisión, la fidelidad y la responsabilidad" del indígena ante al patrón minero: "Comúnmente los arrieros son fieles y dignos de confianza, llegando más pronto ó más tarde á su destino, sea éste á diez ó á quinientas millas, cualquiera que sea la condición del tiempo ó de los caminos. No hacen viaje de andarines, porque la llama y el indio tienen aversión común á la velocidad" (Wright 1907:336).

El proceso estuvo marcado por la emergencia de acontecimientos que incorporaron una novedad procedimental en Pulacayo, un fenómeno que indicó un hito social. Acción capitalista que marcó un trasfondo que moldeó estos acontecimientos, atravesados por la tensión entre reproducción de las constricciones que la preceden y la introducción de novedad y diferencias (Ema 2004). En ese sentido, surgió el anudamiento en un nuevo proceso, en un novato devenir de posibilidades, el movimiento en un escenario de condiciones que buscan dar la imposibilidad al otro. La expresión de una relación colonialista que situó de modo distinto a las mujeres indígenas y a los arrieros, que pasan a transformarse en un cuerpo con un número que transfiere utilidad para la productividad, entendida desde la compañía minera. Una nueva forma de relación que indicó el pronunciamiento de la otredad.

Así, entendida la acción/acontecimiento administrativo y económico que supone un salto, una discontinuidad en donde se produce una inflexión de lo posible hacia lo imposible, surge un campo de relaciones estructurado que, a su vez, indica una interrupción, discontinuidad, una diferencia que se abre (Ema 2004). En ese escenario, el mundo indígena fue articulado con una colonización industrial que impone nuevos parámetros y lógicas de producción, circulación y enlace a saberes tradicionales. (Figura 4).

\section{Revolución mecánica y urbanización}

Schumpeter considera el proceso de producción como una combinación de fuerzas productivas, las que están compuestas por fuerzas materiales que remiten a los llamados "factores originales de la producción": factor trabajo, factor tierra y factor capital. Pero también por las fuerzas inmateriales, compuestas por los "hechos técnicos" y los "hechos de organización social" (Schumpeter

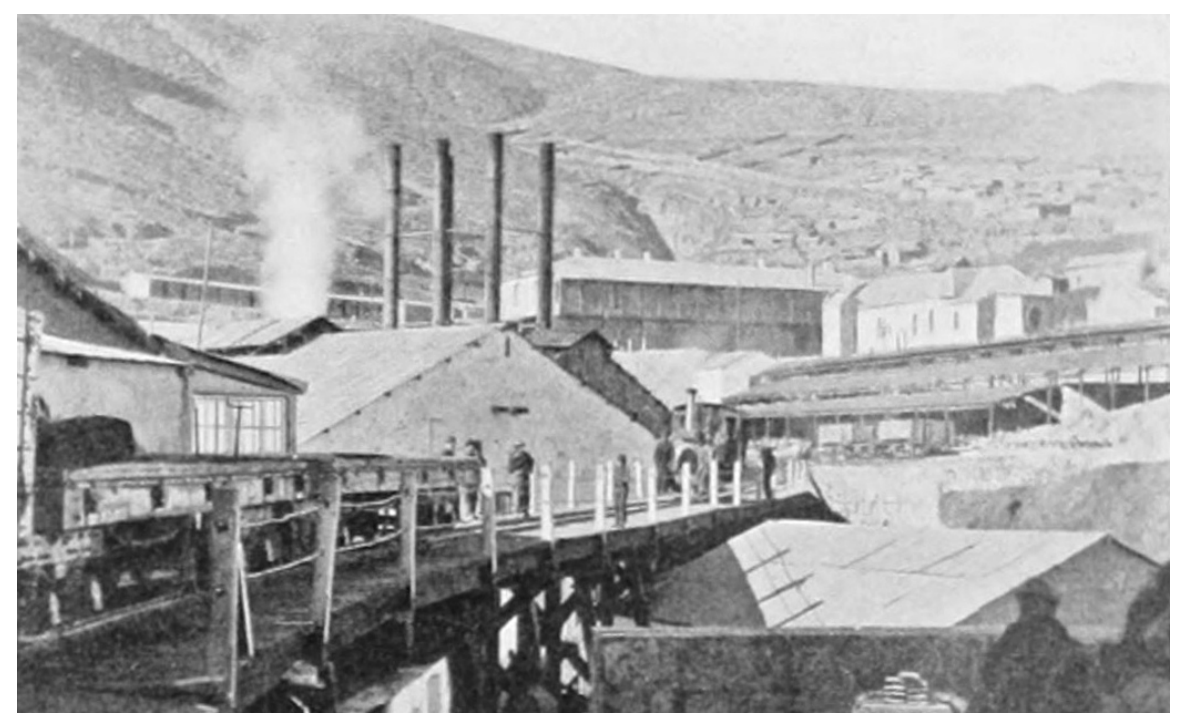

Figura 4. Vista general de las instalaciones en la mina Pulacayo, 1905. Archivo (C) Juan Colque. 
1978) que, al igual que los factores materiales, también condicionan la naturaleza y el nivel del desarrollo económico. En esa dirección, sostuvo que los efectos de los cambios tecnológicos y sociales (tecnología, innovación y ambiente sociocultural) ejercen un impacto más decisivo y más dinámico; por esta razón, estos factores inmateriales fueron denominados por Schumpeter "fuerzas o factores del desenvolvimiento económico o evolución económica" (Schumpeter 1978: 28).

En ese sentido, el "hecho técnico" crucial lo vemos en que, en el nuevo escenario geopolítico de la postguerra, el resultado de la explotación del mineral de Pulacayo había alcanzado gran notoriedad: el directorio de la compañía, en vista de los fastuosos resultados obtenidos en los años anteriores, del porvenir asegurado del mineral, proyectó unir Pulacayo con el puerto de Antofagasta a través de un ferrocarril ${ }^{20}$, "aprovechando de sus ventajas para aumentar la producción de la mina, llevando maquinarias de gran poder i cuya necesidad se hacia ya sentir a medida que se profundizaba su laboreo" (Bobiller 1897: 176). Es así que el ferrocarril inaugura una "fuerza y factor del desenvolvimiento económico y evolución económica" (Schumpeter 1978).

En 1884, la compañía Huanchaca, en conjunto con la Compañía de Salitres de Antofagasta, obtuvieron del gobierno de Chile la concesión para la prolongación del ferrocarril de Pampa Alta hasta Ascotán.

\section{El Decreto Supremo No 690 indicó:}

"Se acepta la propuesta de la compañía Huanchaca de Bolivia, para la construcción de un ferrocarril partiendo de Ascotán. La compañia Huanchaca de Bolivia, se compromete a construir por su cuenta y a sus espensas, un camino de hierro desde Ascotán hasta la ciudad de Oruro pasando por el establecimiento de Huanchaca. (...) El gobierno cede en propiedad, los terrenos precisos para la construcción de almacenes, estaciones y depósitos de agua con arreglo a mensura oficial y el terreno de la corrida de la linea férrea, en toda su estensión, permitiéndole la expropiación de las propiedades particulares que cruce el ferrocarril, con estricta sujeción a las prescripciones generales de la lei, y a costa de la compañia" (AGOB, DS No 690, 29 de noviembre 1888).

La situación de privilegio hacia la compañía quedó explicita en lo siguiente:
"Serán libres de derechos aduaneros todos los materiales indispensables y estrictamente necesarios para la construcción, equipo, y conservación de la línea, tales como máquinas, carros, rieles, durmientes, maderas de construcción, fierro, acero, herramientas, carbón, cal, cimiento, ladrillos, pólvora, dinamita, sacos, telas, clavos, pinturas, alambres, brea, vidrios, máquinas de destilación, calentadores, pizarras, calderos, fondos, planchas de fierro y de cobre" (AGOB, DS No 690, 29 de noviembre 1888).

Las líneas para el ferrocarril estuvieron concluidas desde Antofagasta hasta la zona de El Canchón (futuro Uyuni) a principios de 1889 , con una longitud de 610 kilómetros (Arce 1930).

Todo este proceso, sin duda, mejoró ostensiblemente las ganancias pecuniarias del consorcio porque, por efecto de la llegada de maquinarias de gran poder, mejoraron las condiciones de explotación del yacimiento, obteniendo mejores metales y mayores cantidades, ahorrando también el tiempo de traslado hasta el puerto. El ferrocarril también facilitó el envío de material de menor de calidad para que fuese procesado en Antofagasta.

Consecutivamente, el ferrocarril comenzó un proceso de borradura hacia las rutas de los fotografiados arrieros mineros. Sucumbieron los nombres de algunos empresarios carretoneros que dependían de la compañía Huanchaca, entre ellos Ruperto García, Jorge Casanova y Anselmo Rodríguez (López Pérez 2011).

Este proceso de mecanización trajo aparejado un proceso de urbanización: a 22 kilómetros de la zona minera de Pulacayo estaba el sector conocido como El Canchón. Hasta allí llegó el ferrocarril y surgió una estación: facilitaron esta decisión las características topográficas y

20 El ferrocarril fue emprendido por la Compañía de Salitres de Antofagasta, pero solo llegaba hasta la estación de Pampa Alta, en una longitud cercana a los 100 kilómetros. El convoy atravesaba las pertenencias salitreras de esta compañía, transportando hacia la costa los caliches para ser beneficiados (Recabarren 2002). 
también políticas ${ }^{21}$, propicias para inducir un desarrollo urbano.

En ese sentido, surgieron una serie de disposiciones del gobierno que resuelven la fundación de Uyuni. El primero de ellos tiene que ver con el artículo $\mathrm{N}^{\circ} 18$ de la ley del 25 de noviembre de 1889, la que se ratificó por la ley del día 5 de noviembre de 1889 .

El artículo No 18 mencionó: "Se autoriza para que en caso de que insistiendo la empresa Huanchaca, en construir un ferrocarril por el trazo de Uyuni, parte el establecimiento con un ramal de la posta de Uyuni a Allita, bajo las condiciones generales de la propuestas."(AGOB, DS $\mathrm{N}^{\circ} 690,29$ de noviembre 1888).

21 No obstante, podemos agregar algunas de las motivaciones políticas que llevaron a que la estación fuese instalada en el lugar que hoy la conocemos: Aniceto Arce era considerado en Bolivia como un "chilenófilo" o derechamente como "traidor a la patria" por sus buenas relaciones expresadas con empresarios chilenos (Arce 1930; Mesa et al. 2007; Recabarren 2002). A la hora de saberse el proyecto ferroviario de compañía Huanchaca, surgieron grupos nacionalistas que se opusieron tenazmente a este proyecto, por considerarlo como una nueva invasión chilena (Arce 1930; Recabarren 2002). Por ello, se decidió que el ferrocarril solo llegaría hasta el punto de El Canchón (Bobiller 1897; Arce 1930). Isaac Arce habla de "cierta prensa que decía que la conquista de Bolivia por parte de Chile era ya una realidad, y que no quedaba más remedio que castigar a los traidores que habían entregado maniatado el país a la insaciable codicia de su enemigo de siempre." (Arce 1930: 161). La inscripción de la frase "Ferrocarril de Antofagasta a Bolivia" generaba suspicacias en grupos nacionalistas con repulsión a Huanchaca. "Esta inscripción equivale a decir que Chile está en posesión de Bolivia y que el potentado de Huanchaca es el protagonista de este drama. 'Ya no hay Bolivia, todo está consumado' (...) el pueblo, siempre dispuesto a dar crédito a tales cosas, empezó a hostilizar al ferrocarril por todos los medios que la maldad le sugería..." (Arce 1930: 162). Los atentados a la vía para generar descarrilamientos fueron dando paso a accidentes, a turbas descontroladas contra el convoy, en una trama de un nacionalismo herido de la postguerra.

22 La concomitancia entre Estado - socio fáctico - y la compañía quedó nuevamente explicitada cuando se pretendió nombrar a Uyuni como Ciudad Arce: "Que el señor Presidente de la República no acepta, aunque agradece debidamente, la honra que la compañía ha querido dispensarle denominando Ciudad Arce, a la población que en aquel punto debe establecerse" (AMU, legajos $\mathrm{s} / \mathrm{n}$, Actas y concesiones del Ministerio de Hacienda e Industria. La Paz, 11 de julio de 1889).
No obstante, el antecedente clave fue la concesión otorgada por el gobierno boliviano a la compañía del ferrocarril, con fecha 11 de julio de 1889. En ese decreto de concesión, se establecían los detalles de la entrega:

"Se autoriza la creación de una nueva ciudad bajo este nombre, adjudicación de lotes a la compañía del ferrocarril. Vista la anterior solicitud y considerando: que según el artículo 10 de la lei de 29 de noviembre de 1888, el gobierno está obligado a ceder a la compañía Huanchaca de Bolivia, los terrenos precisos para la construcción de almacenes, estaciones, depósitos, etc. Que el punto de Uyuni, por su situación topográfica y los recursos naturales con que cuenta, está llamado a ser un centro de población" (AMU, legajos s/n, Actas y concesiones del Ministerio de Hacienda e Industria. La Paz, 11 de julio de 1889) ${ }^{22}$.

\section{Finalmente se resolvió:}

"Autorizase la creación de una ciudad en el kilometro 610 de la vía de Antofagasta a Pulacayo, bajo denominación de Ciudad Uyuni y conforme al plano presentado, y que se archiva en este ministerio. $2^{\circ}$ Adjudicase en propiedad a la compañía del ferrocarril de Antofagasta a Huanchaca (...) una área de terrenos de un kilometro de largo por 500 metros de ancho, para la estación Uyuni del ferrocarril de Antofagasta a Pulacayo. Arce-Tamayo." (AMU, legajos s/n, Actas y concesiones del Ministerio de Hacienda e Industria. La Paz, 11 de julio de 1889).

La llegada del ferrocarril y el surgimiento de la ciudad de Uyuni facilitaron aún más el proceso migratorio hacia la zona del altiplano, configurándose una ciudad multinacional. Algunos historiadores hacen mención a la llegada del hombre "blanco" (Pérez López 2011; Chungara s/f), indicando que la inmigración fue estimulada por "la creación de fuentes de trabajo de la empresa minera de Huanchaca y la iniciación de los trabajos del ferrocarril" (López Pérez 2011: 44).

El mismo André Bellessort (1897) daba cuenta, en su viaje desde Antofagasta hasta Uyuni, de un ferrocarril con alta presencia de extranjeros que se dirigían a la nueva ciudad, entre ingleses, peruanos y franceses.

Alberto André nos comentó lo siguiente: “Uyuni pasó a ser de la nada, al todo de Bolivia. Acá no había nada, y de pronto surge una población de gringos, ingleses, alemanes, turcos, eslavos...venían de todo el mundo a tratar de 
ganar dinero, gracias a todo lo que generaban la minas, que están bastante cerca de la inicial planicie" (Com. personal André 2013).

Por su parte, Vidal López (2011) afirma: "desde ésta época predominaron eslavos, sirios e ingleses, funcionarios que prestaban servicios en la Railway" (López 2011: 44). Las familias más numerosas eran los Ivanovic, Marincovic y Orlandini. La ciudad también se fue poblando gracias a los obreros y campesinos, que en gran parte provenían desde las salinas de Garcí Mendoza, todos dirigidos hacia el ferrocarril. Otros provenían desde Cochabamba (Chungara, s/f) $)^{23}$.

Sobre Uyuni, se dijo que era "una población improvisada, por la construcción de la línea férrea, y pequeña ciudad, ó mejor, proyecto de ciudad" (BIGA 1894: 426). Por su parte, André Bellessort, en su paso por Uyuni en 1895 , desde su mirada etnocéntrica y racista hace una breve reseña sobre el pueblo en conformación, apuntando a cierta agencia de bricolaje de la materialidad industrial por parte de los habitantes: "Me paseaba por Uyuni, que es el pueblo más espantoso que conozca, todavía peor que Calama. Se acusa a los habitantes de haber construido sus casas con durmientes robados al ferrocarril. Cinco o seis palmos de calles sucias, sórdidas, entre una montaña verdosa y la inmensidad de la pampa pelada" (Bellessort 1897: 109).

En base a los archivos municipales de Uyuni, en especial en lo consignado en el Plano y Guía Comercial de la ciudad, emitido en 1909, podemos identificar la presencia de comerciantes inmigrantes en la nueva urbe, con almacenes ubicados en las calles aledañas a la estación de ferrocarriles, entre ellos: Cosme Soldanere, Ivanovich Hnos., Gustavo Hinkez, Luksic Yutronic \& Cía., Fernández Riana \& Cía., Aramayo, Francke \& Cía., Danelsberg Shubening \& Cía., Pakoma, Rosazza \& Cía., Nicolás Arguelles, Savoia Hermanos, Jorge Barrau, Emigdio Arostegui, Ugrinovic Hermanos, Rodolfo Fridriche, Donato Aranivar, Pedro Barrau, A. Ivanovich, Marcos Pavisich, Max Subosch, entre otros tantos; todos ellos dedicados a importación directa de mercaderías en general, agencias de aduanas, comisiones y consignaciones, servicios de ingeniería, importación de maquinarias, agencias de dinamita, pólvora, azufre y sal para ingenios, importación de coñac, whisky, vinos. También pequeños bancos, importación de aba- rrotes, empresas tipográficas, imprentas, empresas fotográficas, "artículos de novedad desde Europa", casas de cambios de monedas, hoteles, labores de mecánica, etc. (AMU, Plano de la ciudady guía comercial de 1909).

Gran parte de los comerciantes reseñados eran inmigrantes alemanes, españoles, ingleses, eslavos, chilenos y unos pocos bolivianos. De esta forma, se manifestaba un comercio multiétnico y multinacional. Este proceso de inmigración adquirió rasgos colonizantes, según los relatos de nuestros informantes, en cuanto a que estos europeos llegaron apatronando a los indígenas.

Alberto André señala que las clases sociales estaban compuestas por una elite de claro origen inglés: "ellos —los ingleses - eran los futres, los mejores vestidos y los más refinados. Todos estaban vinculados con los servicios de la Railway. Pero también había sirios, yugoslavos, turcos, todos ellos dedicados al comercio, a los almacenes. La Huanchaca generó mucho movimiento económico" (Com. personal André 2013).

Los considerados como burguesía minera y ferroviaria eran los ingleses ${ }^{24}$, el resto de los inmigrantes europeos se dedicaron, usualmente, al comercio. En este imaginar, la clase baja eran los obreros y los mineros de Pulacayo. Generalmente, la gente del campo fue reconvertida al rubro minero. Como es de suponer en la lógica raciológica decimonónica y de principios del siglo XX, la condición de indígenas facilitó un enlace para formar proletarios, desplegados en el trabajo duro, bruto y físicamente peligroso en las ardientes minas argentíferas. Las setenta

23 Algunos historiadores bolivianos consideran que la afluencia de campesinos era mínima por no poseer esta nueva ciudad una "tradición agrícola" (Chungara s/f; López Nina 2005; Mamani 2010).

24 En el caso de eslavos vinculados con el ferrocarril, Rómulo Calvo nos menciona a Ramón Dabeti'c y Pedro Medi'c, contratistas que estuvieron a cargo de la construcción del Edificios para Almacenes y Pulpería, la construcción de la Casa de Máquinas, Talleres de Vía y Obras, también habrían levantado el Taller de Calderería, el estanque de enfriamiento, el taller de reparación equipo pesado, ocho viviendas para el personal superior, Edificio Usina Eléctrica y la extensión Taller de Montaje o Armaduría. Además, nos indica la construcción de un puente grúa para levantar locomotoras, obra a cargo del ingeniero George H. Smith (entrevista, febrero 2014). 
horas de trabajo semanal no eran cuestionadas (López Pérez 2011), se trabajaba en condiciones de precariedad al límite (Com. personal André 2013).

La implementación y administración del ferrocarril por parte de The Antofagasta and Bolivian Railway Company, estimuló la llegada a Uyuni de ingenieros y técnicos ingleses para gestionar las líneas férreas. Esta compañía posibilitó la construcción de una serie de equipamientos públicos y recreativos (Marinkovic 2011).

En este escenario, los bolivianos, los indígenas, los campesinos, los mineros, atestiguaron una inmigración que obtuvo una acumulación financiera sustancial en los márgenes del sur boliviano. Las diferencias materiales y de calidad de vida entre los europeos y los bolivianos fueron profundas. Fueron muchos los elementos que marcaron una gran diferencia entre el boliviano, marcado por su "morenidad", y el europeo, diferenciado fenotípicamente con el autóctono. Eran los efectos de los imaginarios decimonónicos, centrados en la supuesta superioridad cultural del europeo. Contribuía en ello la educación eurocentrista, las estructuras sociales heredadas de la época de la colonia española, la política raciológica de Bolivia - en donde cotidianamente se despreciaba al nativo ${ }^{25}$ - además de las teorías evolucionistas y positivistas. Ese mismo imaginario eurocéntrico contemplaba a Europa como cuna de la civilización y desarrollo. Estos inmigrantes europeos se transformarían, en el transcurso de su estancia, en empleadores de los bolivianos, y se constituyeron elite local, vinculada a la política, comercio y empresariado minero.

\section{Estratificación y representación}

Las determinaciones o injerencias dadas por inmigrantes europeos hacia la nueva ciudad tienen estrecha relación con el proceso de urbanización y ordenamiento.

La planificación urbana surge en torno a la estación de ferrocarriles. Asimismo, aquel punto centrífugo y centrípeto de los convoyes, se convirtió en un nudo de articulación entre estación y mina, entre estación y pueblo. La estación funcionaba como imán, potenciado por la expansión del nuevo ayuntamiento.

Desde la estación ferroviaria uyunense se modeló la ciu- dad, y en ella podemos detectar un fuerte rasgo de "racionalidad y funcionalidad" para los colonizadores, porque al ser una ciudad proyectada desde la estación, por parte del ingeniero brasileño Julio Pinkas, se pensó en los sistemas de construcción, en las formas de emplazamiento y distribución urbana en base a un racionalismo damero. De esta distribución, como era de suponer, derivó una organización clasista (iacaso etnológica?), diferenciada por jefaturas, comerciantes (residentes en el centro de la ciudad) y las periferias para obreros, mecánicos, peones y mineros, en su mayoría indígenas (Chungara s/f; López Pérez 2009).

Lo que comenzó a ocurrir en Uyuni en los finales del siglo XIX no distaba mucho de lo que había acaecido en Pulacayo, en cuanto a la conformación de un poblado organizado y dividido en sectores diferenciados materialmente: viviendas insalubres y precarias ocupadas por obreros; zonas residenciales para empleados; zonas exclusivas para empleados extranjeros. Las zonas exclusivas estaban rodeadas de alambrada y no se permitía el tránsito de obreros o gente ajena a la empresa. ${ }^{26}$ Cabe indicar que las condiciones de vida en la mina de Pulacayo, hacia 1906, eran deplorables para los indígenas, los salarios apenas cubrían las necesidades básicas de subsistencia. Un maquipura ${ }^{27}$ y el barretero ganaban un peso diario por una jornada de 18 horas; el apiri ${ }^{28}$ recibía entre veinte y cuarenta centavos, y las palliris, no más de veinte ${ }^{29}$ (Flores y Martínez 2009).

25 El Censo General de la Población de la República de Bolivia del año 1900 reveló la existencia de una población "no civilizada" o "no sometida", que bordeaba las 91000 almas. Ver: Censo General de la Población de la República de Bolivia según el empadronamiento de Iro. de septiembre de 1900 (Oficina Nacional de Inmigración, Estadística y Propaganda Geográfica de Bolivia, 1902).

26 El informe Bloomfield, elaborado en 1947, estableció que, "no obstante mejoras introducidas en los campamentos, muchas de las viviendas para trabajadores en ciertos casos, aún en las grandes minas, consisten en miserables, oscuras e insalubres chozas de un solo cuarto, inapropiable para el uso humano". El informe concluía que los mineros vivían en pocilgas. Ricardo Anay subrayó, en "pocilgas para mineros, porque los cobertizos para cerdos de Pairumani son mejores que las viviendas de millares de jornaleros de estas minas" (Flores y Martínez 2009). 
En el caso de Uyuni, ${ }^{30}$ comienza una nueva representación, una inscripción visual, material y simbólica: se instala un gran reloj en la calle principal, constituyendo la plaza de la ciudad. Un obelisco cronométrico destacado a lontananza en el altiplano.

En el año 1926, variadas personalidades empresariales, a la cabeza del párroco Luis Buitrago, más Eudoro Calvimontes, Pedro Ugrinovich, Miguel González y Natalio Cardozo, organizaron actividades destinadas a financiar la compra del reloj, el cual finalmente fue adquirido en Hamburgo (AGOB, Decreto Supremo 690, 22 de febrero 1929).

La torre del reloj, que funciona desde 1930, se configuró como centro de atención y conglomeración, pero, por sobre todo, de identificación de esta nueva ciudad. Siendo la defensa ciudadana hacia el reloj una actitud irrestric$\mathrm{ta}^{31}$.

Hermenéuticamente, el reloj lo podemos comprender desde el lenguaje industrial de la modernidad. Desde la óptica de una maquinaria que mide tiempo orientado hacia la población indígena. Quizás es un lenguaje construido desde un enfoque biopolítico, de control social, de control del cuerpo, o como dependencia del cuerpo a un sistema capitalista, dirigido hacia una etnicidad moldeada por las actividades mineras y ferroviarias: el reloj como representación de la "racionalidad" y el "orden". En donde los uyunenses no eran más que unas "máquinas" al servicio del capital, como resultado de una mecanización industrial impulsada por Huanchaca, mecanización que se trasladó a las personas. Es una acción que surge del seno de la ciudadanía, que ya había asumido la hegemonía del lenguaje productivo dado por las compañías extranjeras hacia el naciente poblado.

A una cuadra del reloj se construyeron la iglesia y las escuelas. Al costado del reloj, hallamos el edificio consistorial y la plaza. Entonces, desde la línea hacia el norte que proyecta la estación de ferrocarriles, se trabaja, se sociabiliza, se desfila, se reza, se educa, se marcha y se baila en tiempos de carnaval.

\section{Discontinuidades arrieras y aduanización}

Con la implementación del ferrocarril se evidenció el aumento de los volúmenes de carga de mineral, permitiendo la construcción de la fundición en Playa Blanca (Antofagasta); dinamización comercial con la configuración de un "puerto seco" en Uyuni y el declive de los caravaneos mineros hacia la costa (Vaïsse 1894). Dichas vías contribuyeron a romper los circuitos habituales de intercambio e introdujeron algunas dislocaciones en el territorio.

En ese escenario, los arrieros comenzaron a trazar una nueva inscripción, reordenando sus rutas transfronterizas para participar en los nuevos procesos comerciales en una ciudad que atestiguó las repercusiones de un proceso de industrialización.

Entonces, los administradores del Estado, visto el agenciamiento indígena en cuanto a la configuración de nuevas territorialidades (Benedetti y Salizzi 2011) y rutas

27 Obrero temporario, "es un paria, no se le reconoce ningún derecho y es descendiente directo de los mitayos y los mingrados de la colonia" (Almaraz 2009: 478).

28 Operario que transporta mineral en las minas.

29 Según los cálculos realizados por Flores y Martínez (2009), en el año 1906 un peso boliviano equivaldría a seis dólares.

30 El primer plano de la ciudad data desde 1903 y encarna un trazado a escala 1:2000 con sus calles de 100 metros de largo por 20 metros de separación entre cada cuadra. El total llega hasta las 440 manzanas, con lotes numerados de a 12, y que están dispuestos uniformemente (AMU 2013). Los empresarios, con la cooperación del Estado boliviano, edifican la Escuela Femenina Juana Azurduy de Padilla y la Escuela de Hombres Aniceto Arce. Luego, construyeron el Banco de la Nación Boliviana, el teatro municipal, el edificio de correo, la aduana nacional. Además, surgió el hotel Uyuni, el edificio municipal y conglomerados de casas construidas con maderas.

31 Estos hechos de "defensa del reloj" fueron inaugurados cuando el municipio de Tarija se lo quiso llevar, vistas las deudas del municipio de Uyuni en la década de 1930, hecho ocurrido en el primer lustro de la década del treinta. Frente a la resistencia de los vecinos, se organizó un cabildo para plantear el peligro que conllevaba este "apresamiento" del símbolo uyunense (Com. personal André 2013).

32 Al respecto, Vaïsse (1894) indicó: “Desde que se suprimió el puerto de Cobija i se estableció el ferrocarril de Antofagasta a Bolivia, la arriería que antes era la principal industria de los atacameños, está moribunda, sino ya muerta. Pocas son las tropas que actualmente trabajan, (...) el negocio no es remunerador". 
por efecto de la circulación - lo que facilitó un proceso de vulneración de fronteras-, consideró ineludible reglamentar y controlar la gran cantidad de mercancías que comenzaron a circular por la zona. Estos movimientos fueron denunciados como "contrabando".

El primer Decreto Supremo boliviano surgió el 29 de julio de 1892, estableciendo una oficina en Uyuni para controlar el masivo despacho de las mercaderías que se internaban por el ferrocarril de Antofagasta: "La terminación del ferrocarril de Antofagasta á Uyuni, impone el establecimiento de una oficina especial destinada al despacho de mercaderías que se internen por aquél puerto á las poblaciones de Bolivia. Que dicha oficina facilitará los procedimientos aduaneros y consulta los intereses del comercio" (AGOB, Decreto Supremo 29 de julio 1892).

En cuanto a los detalles del establecimiento, se estableció una oficina encargada del control del aforo de mercaderías nacionalizadas, que se internaban por la vía de Antofagasta para el consumo de los departamentos situados al norte de la línea férrea y para el despacho de las que estuviesen en tránsito por el mismo puerto.

Seguidamente, en el año 1900, el Estado boliviano decreta supremamente el resguardo a través de un comisario: "Se crea resguardo entre Uyuni y la frontera provisional de Chile", mencionaba el decreto del presidente José Manuel Pando, que más adelante precisaba:

"Que en la región comprendida entre la ciudad de Uyuni y la frontera provisional de Chile, no existe resguardo aduanero alguno, sin embargo de que en la parte media hay la Estación del Río Grande. Considerando que la industria está alcanzando un desarrollo de importancia considerable en la vasta región situada entre el Sury de Uyuniy que es necesario prestarle las facilidades posibles. Que además, tiene el Gobierno la obligación de adoptar todas las medidas conducentes á la correcta perfección de ellos; previo acuerdo de los señores Ministros de Estado". (AMU, Decreto 28 de abril de 1900, folio $s / n$ ).

Entre los variados artículos del decreto para establecer el control fronterizo, uno de ellos hizo mención a la creación del "Resguardo y Comisaría de Aduana", con la misión de funcionar en la región situada al sur, oeste y norte de Uyuni y a lo largo de la línea provisional que servía de límite con Chile, desempeñando en ella las funciones de policía aduanera. Dicho resguardo poseía el servicio de vigilancia de la importación legal de alcohol y aguardiente extranjero. Para ello, el personal del resguardo estuvo compuesto por un jefe, tres subalternos y 25 vigilantes "dotados del equipo necesario", incluyendo armas (AMU, Decreto 28 de abril de 1900, folio s/n).

El mismo decreto indicó la contratación de un guardia aduanero ambulante, que llevaría sus funciones en el ferrocarril entre las estaciones de Uyuni y Ollagüe, para evitar actividades de contrabando.

“(...) para lo que fuere necesario hará las gestiones conducentes el señor Ministro de Gobierno y en su caso el de Relaciones Exteriores ante quién vieren convenir (...) conforme con las instrucciones que comunicará el Administrador de la Aduana de Uyuni, el Resguardo vigilará además la carga y descarga en la Estación de Río Grande, de los artículos destinados al consumo de la región situada entre la ciudad de Uyuni y la frontera provisional" (AMU, Decreto 28 de abril de 1900).

Era evidente que se buscaba intervenir sobre los flujos en contravención de productos llegados desde Chile (Antofagasta y Calama); se habían descontrolado, por parte del Estado boliviano, las dinámicas y los flujos en la frontera. Se imprimió, de este modo, un carácter ambulante de la aduana, basada en los recorridos por los vastos sectores de la frontera. Una policía ambulante que solo buscaba detener los flujos considerados como contrabandistas, los cuales eran liderados por antiguos arrieros mineros considerados expertos baqueanos de la zona (Com. personal André 2013).

Fueron numerosos los decretos del poder ejecutivo, estableciendo atribuciones extraordinarias o indicando la inversión en logística con el propósito de detener la actividad "ilícita". Por ejemplo, el 5 de diciembre de 1901 se creó la "fuerza de resguardo", para evitar el ingreso de alcoholes por el sudoeste del país. En el detalle del decreto, se indicó lo que sigue:

"Considerando que, los contrabandos de alcoholes en la frontera Sud Oeste de la República, toman proporciones alarmantes y considerables por falta de una fuerza de resguardo que los vigile. Que los pocos Jefes y Comisarios de resguardo son insuficientes para evitar este mal que sigue un creciente desarrollo, puesto que 
muchas veces los contrabandistas consuman el delito en gran número y armados. Que el contrabando es un mal que cede en perjuicio de las rentas nacionales é implica defraudación de fondos fiscales. Se decreta: Artículo $I^{\circ}$ Créase una fuerza ambulante de resguardo, de cincuenta hombres en la frontera Sud Oeste de la República. El objeto será el de evitary aprehender los contrabandos ó internaciones clandestinas" (AGOB, Decreto Supremo $\mathrm{S} / \mathrm{N}, 5$ de diciembre 1901).

Seis años más tarde, el presidente Ismael Montes ordenó la concentración en Uyuni de las operaciones de la Agencia Aduanera de Antofagasta. Lo anterior era decretado el 30 de noviembre de 1907.33

Los artículos contenidos en el decreto indicaron lo siguiente: "Desde el $1^{\circ}$ de enero de 1908, se reconcentrarán en la Aduana Nacional de la ciudad de Uyuni, todas las operaciones de despacho y aforo de mercaderías de la Agencia Aduanera de Antofagasta." (AGOB, Decreto Supremo del 30 de noviembre 1907).

Pese a una gran cantidad de medidas por parte del poder ejecutivo boliviano, los flujos de internaciones clandestinas siguieron operando. La porosidad de la frontera boliviana, sus vastas extensiones, las sempiternas rigurosidades del clima, el conocimiento de la región por parte de antiguos arrieros, hicieron posible una noción de descontrol por parte de las autoridades estatales de Bolivia.

Sin embargo, ante el escenario postguerra, la nueva geopolítica y, por sobre todo, la escena de un enclave económico en este nuevo contexto, los caravaneros y arrieros de ambos lados de la frontera debieron utilizar "clandestinamente" las postergadas rutas históricas para mantener un comercio e intercambio que, ahora, era calificado como un delito de contrabando, surgiendo las respectivas criminalizaciones (Com. personal André 2013).

Por un lado, se atestiguaban, efectivamente, actividades de contrabando, pero también existían actividades arrieras y de caravaneo que permitieron la continuidad práctica de la complementariedad entre comunidades del altiplano y precordillera de Atacama. Entre Atacama y Bolivia se intercambiaba harina y chicha de algarrobo $y$ los frutos del chañar, por cueros de chinchilla, hojas de coca y ají, provenientes del altiplano. El chañar, adquirido en Atacama por los arrieros bolivianos, era un producto muy apreciado en la zona de Lípez. El proceso de aduanización lidió con un mercadeo indígena que satisfacía necesidades de consumo, combinando la utilización de monedas de distinto origen: los arrieros andinos complementaban lógicas mercantiles con prácticas tradicionales (Sanhueza 2012).

Este proceso, además, puede ser entendido como una reconversión que viven los indígenas. En cuanto a la arriería, al situarse con una importancia disminuida por efecto de la guerra del Pacífico y la construcción del ferrocarril en 1889-1891, la mayoría de los arrieros se vieron obligados a volcarse hacia el mercado creciente de la sal entre los ingenios de la vertiente oriental. Esta contracción arriera, que confluía con la crisis metalúrgica para consolidar un proceso de desmonetización progresiva para las economías domésticas, hizo crecer la participación del trueque. Esta "reconstrucción de tendencias seculares" daría paso a migraciones estacionales de los indígenas para cumplir con el pago de tributos, fruto de un escenario hostil, debiendo acudir a otros productos (Platt 1987).

En esa escena de discontinuidad, atestiguamos procesos de movilidad por parte de arrieros que decidieron radicar en distintos poblados incorporados a Chile desde 1879, todos provenientes desde la zona de Potosí. Gracias al Archivo de Extranjería del Registro Civil e Identificación

33 El 4 de noviembre de 1916, visto que la Aduana Nacional del Sudoeste (Uyuni) fue elevada a la categoría de oficina de aforos para el despacho de las mercaderías internadas por la vía de Antofagasta, se hizo necesario nivelar la fianza de los agentes despachadores, que funcionaban ante ella con la que prestaban ante las oficinas de igual carácter, conforme al Decreto Supremo de 10 de agosto de 1911, en uso de atribución constitucional. Ismael Montes decretó lo siguiente: "Art. $1^{\circ}$ Los Agentes Despachadores ante la Aduana de Uyuni deberán prestar la fianza de veinte mil bolivianos. Art. $2^{\circ}$ Los Agentes que funcionan actualmente, están obligados a elevar el monto de sus fianzas a Bs. 20,000 hasta el 31 de diciembre próximo, bajo la pena de suspensión de funciones. Dado en el Palacio de Gobierno de la ciudad de La Paz, a los cuatro días del mes de noviembre de mil novecientos diez y seis". (AGOB, Decreto Supremo del 4 de noviembre 1916). 
de Antofagasta, que a través de prontuarios archivó el ingreso de bolivianos después de la guerra, podemos identificar $22 \operatorname{casos}^{34}$. (Ver Tabla 1).

Estas movilidades se evidencian deconstructivamente sobre la frontera (Hevilla 1998; Pries 2002; Bartolomé 2008; Beck 2008), manifestando la vigencia de las redes sociales y las relaciones interpersonales (González 2008) en escena de "policiamientos" (GEPyFS 2012). La deconstrucción a fronteras estatales y capitalistas, inclusive al concepto mismo de migración, se diluye porque eran los mismos territorios de los sujetos regionales. No podemos afirmar, pero tampoco descartar, que estos arrieros dejaron sus tierras, quizás, para reconvertir sus labores en un contexto de decadencia arriera.

La tendencia a la bolivianización territorial con la disposición de aduanas y los constantes estímulos pecuniarios para el personal no fueron suficientes para detener estas tensiones. No obstante, las primeras décadas del siglo $\mathrm{XX}$ se caracterizan por una intención resuelta del Estado boliviano de querer intervenir la zona, marcar una presencia en un escenario en donde aún resonaban los recuerdos de una reciente guerra.
El llamado "contrabando" era estimulado por diversos factores: la escasez y carestía de mercados en el sur de Bolivia, la novedad y diversidad de productos, algunos de primera necesidad, otros netamente suntuarios y algunos considerados por los vecinos de Uyuni como "viciosos": alcohol o cigarros. La diversidad de productos fue la característica de lo contrabandeado (Chungara s/f; López 2009).

Por otra parte, existen versiones que indican que los contrabandistas contaban con cierto fuero social, poseían redes de apoyo diversas: "desde amigos, policías, políticos y tantos otros..." indica Condori (Com. personal 2013). La actividad poseía cierta estabilidad porque se constataba la corrupción de funcionarios, las irregularidades de las comunicaciones, la ambigüedad y contradicciones en la aplicación e interpretación de las leyes, la ineficacia e insuficiencia numérica del personal de la policía y militares que no podían sortear la escabrosa geografía y clima

34 Trabajo de archivo realizado gracias al proyecto Fondecyt No 11110246 (2011-2014) "Etnicidad y procesos translocales en espacios de frontera: migraciones internacionales en el norte de Chile". Dirigido por Dr. Alejandro Garcés Hernández.

\begin{tabular}{|c|c|c|c|c|c|}
\hline Nombre del arriero & Origen en Bolivia & Fecha ingreso a Chile & Destino en Chile & Relaciones en Chile & No Prontuario (AERCIAB) \\
\hline Víctor Colque & Llica & 1886 & Yuma & 3 & 20047 \\
\hline Gabriel Urrelo & Potosí & 1899 & Yuma & 4 & 20049 \\
\hline Pedro Rocha & Uyuni & 1904 & Cebollar & 3 & 19993 \\
\hline Noticio Valdivia & Potosí & 1906 & Cebollar & 2 & 19948 \\
\hline Francisco Flores & Oruro & 1906 & Calama & 3 & 19240 \\
\hline Roberto Nina Veliz & Pulacayo & 1907 & Yuma & 4 & 20072 \\
\hline Leandro Gómez & Potosí & 1909 & Cebollar & 6 & 20054 \\
\hline Tiburcio Urrelo & Potosí & 1909 & Collahuasi & 2 & 121134 \\
\hline Isaac Urrelo & Potosí & 1913 & Collahuasi & 3 & 14434 \\
\hline Ignacio Urrelo & Potosí & 1915 & San Pedro de Atacama & 4 & 121135 \\
\hline Esteban Urrelo & San Pedro & 1916 & Cebollar & 2 & 20044 \\
\hline Leocadio Vaca & Potosí & 1917 & Ollagüe & 3 & 90300 \\
\hline Eutaquio Quispe & Llica & 1917 & Yuma & 1 & 20067 \\
\hline Juan Urrelo & Llica & 1917 & Yuma & 2 & 20059 \\
\hline Manuel Henríquez & Pulacayo & 1917 & Calama & 3 & 20073 \\
\hline Gregorio Huayta & Llica & 1919 & Calama & 6 & 20074 \\
\hline Luciano Huaca & Uyuni & 1919 & Cebollar & 5 & 19983 \\
\hline Isidoro Rodríguez & Pulacayo & 1919 & Ollagüe & 2 & 20050 \\
\hline Valenciano Urrelo & Uyuni & 1919 & Puquios & 4 & 20079 \\
\hline Justo Loaiza Urrelo & San Pedro & 1920 & Calama & 4 & 20080 \\
\hline Raimundo Gómez & Uyuni & 1920 & Calama & 2 & 20046 \\
\hline Rufino Martínez & Pulacayo & 1920 & Yuma & 1 & 21055 \\
\hline
\end{tabular}

Tabla 1. Arrieros registrados y prontuariados en su ingreso a Chile entre 1886-1920. Fuente: Archivo de Extranjería del Registro Civil e Identificaciones de Antofagasta, Bolivia. Perteneciente al Archivo histórico UCN, Antofagasta. Esquema: elaboración propia. 
del altiplano, una zona conocida por los arrieros.

Los circulantes altiplánicos se enfrentaban a un nuevo trazado de límites, el cual daba pie a un territorio público que engendró miedos o turbaciones al tratarse de un territorio incontrolado (Garcés 2014) por el Estado, por ello, peligroso para la "estabilidad del país", un espacio en el que la "civilización", en la lógica estatal, era considerada excepcionalmente frágil. En este caso, los usos y saberes indígenas que se demuestran en el espacio público por parte de los considerados contrabandistas, son imaginados como sujetos en una persistencia desobediente, en un deambular como transgresión al orden: una transgresión a la "civilización del país" (Mitchell, 2003).

La frontera de la postguerra se configuró como un territorio en donde se agenciaron nuevas relaciones entre individuos y grupos que manifestaron formas de reapropiación diversa respecto del espacio. De un espacio que es pretendido bajo el control por los afanes del Estado. Surgió una tensión por sus dominios. La constitución de rutas, de posadas, de tambos, nos remiten a una readjudicación de la región, desde una elusión al Estado: una clara señal de modificación del orden establecido, una agencia indígena en un contexto de mercado y clausuras del territorio.

El altiplano, y lo obrado en él, aparece como un trabajo en el cual emergieron o son inventados nuevos modos de vivir, de habitar, de producir, y por sobre todo, nuevos modos de circulación en un anonimato o resistencia anatomopolítica. Surgió, desde este modo, nuevas representaciones del espacio fronterizo. Formas de atropello a lo establecido, como forma de respuesta en discordia al orden hegemónico y la biopolítica del territorio, diseñada por las fronteras geopolíticas de los Estados modernos en cuanto al control de los cuerpos en movimiento (Van der Velde y Van Naerssen 2010).

La respuesta estatal, en ambos países, tiene que ver con la eterna restauración del disciplinamiento del espacio, un espacio diseñado en clausura (Galaz-Mandakovic 2013). Es decir, la especificación y determinación de un lugar heterogéneo a los demás y cerrado sobre sí mismo, lugar protegido y distinto (Delgado 2007), que se inscribe en la monotonía disciplinaria y rígida (Foucault 1975). Se evidencia, entonces, una tensión cartográfica: una que impone los confinamientos, la disciplina, la identificación, el control: una colonización, desde un Estado socio de una empresa, contra otra cartografía que remite a la transgresión y a las practicas pre estatales y pre industriales.

Al respecto, Gottmann (1973) señala que en geografía política, una frontera internacional puede ser considerada una "zona de indeterminada anchura", cruzada por una línea que determina los límites de la soberanía territorial de un Estado, que ve en la demarcación el ejercicio de la soberanía.

Sin embargo, vemos una incompatibilidad entre los "límites fronterizos" y las "áreas de frontera". El límite se admite como la constitución de líneas de disgregación físicas y visibles entre espacios económicos, sociales y políticos. Por su parte, el "área de frontera" es la región o área en relativa proximidad al límite, donde las dinámicas de cambio y cotidianidades están relacionadas por la misma presencia del límite (Newman 2006). Los "límites fronterizos" son obra de los Estados, que a través de instrumentales jurídicos imprimen la separación entre unidades políticas soberanas y delimitan el territorio bajo control estatal; las "áreas de frontera" son construcciones sociales de los sujetos, los cuales se pueden expandir más allá del límite jurídico del Estado, desafiar la ley territorial de cada Estado limítrofe y, a veces, crear una situación de facto potencialmente conflictiva (Machado 2000), tal como el caso de estos arrieros circulantes.

\section{COMENTARIOS FINALES}

Los procesos evidenciados en el transcurrir de casi un siglo deben comprenderse desde un proceso capitalista y revolucionario en el sudeste boliviano. Economía de enclave evidenciada en cinco ejes elementales: infraestructura, mercado, insumos, productividad y macroeconomía.

Hablamos de una infraestructura porque la expansión del enclave envolvió la implementación y disposición de materialidades innovadoras, que facilitaron el desarrollo de las nuevas actividades productivas. El proceso de tecnologización minera y mecánica de transporte también 
dio paso a procesos de urbanización, siendo todo este proceso una versión regional de cierta revolución industrial.

Lo anterior indujo a la expansión de la influencia del enclave, transformándose en un polo gravitacional de mano de obra que, a su vez, demandan bienes de consumo a negocios translocales instalados en las nuevas urbanizaciones, Uyuni y Pulacayo. El poder de consumo fue importante para desarrollar el mercado local y transformar las "concentraciones territoriales regionales" (De Mattos 1984). Esto último dio pie a la conformación de un conglomerado de almacenes y bancos en los finales del siglo XIX y principios del XX, que buscaban satisfacer la demanda integral de los nuevos habitantes y sus actividades mercantiles.

Una economía de enclave, como la que constituyó Huanchaca, facilitó un proceso de re jerarquización de los insumos requeridos en el territorio de implantación. Se demandaron nuevos consumos y servicios locales para generar un círculo virtuoso de crecimiento económico, a través de la conexión con un mercado que pudiese satisfacerlo.

Lo anterior no tendría razón si la concepción de productividad fuese rígida. Por ello, se introdujeron mecanizaciones para los procesos de tratamientos de minerales, siendo brutal la lectura realizada hacia el indígena como parte de un proceso de "maquinización" y de "numerización”; a la postre, un proceso de deshumanización. La productividad como eje moldeó la diversidad cotidiana. Para ello, Huanchaca dispuso de una serie de procesos que facilitaron la productividad. No es casual que Uyuni y Pulacayo fueran vistos como los poblados más tecnológicos de Bolivia ${ }^{35}$ desde los finales del siglo XIX. De todos modos, consideramos que la practicidad y representación

35 La llegada del ferrocarril, los primeros autos, aviones, camiones, telégrafos, teléfonos, potabilización del agua en Bolivia, tienen sus antecedentes en Uyuni y Pulacayo. Además, la conformación de una gran maestranza ferroviaria configuró a Uyuni como la capital mecánica del país (López 2009).

36 Giddens (1986) indica que la agencia se refiere no a las intenciones que se tiene en hacer cosas, sino que a la capacidad de hacer esas cosas; por tales razones, la agencia implica poder. Agencia se refiere a los eventos de los cuales un individuo es un autor, en el sentido de que un individuo podría, en cualquier fase de una secuencia dada de conducta, haber actuado de manera diferente. del reloj no es fortuita. O la reconversión de campesino a minero o mecánico, genera una reinscripción de las biografías del altiplano en aras de producir bienes y servicios eficientes para una compañía inserta en un contexto macroeconómico.

Los indígenas, en la escena industrial del altiplano, se articularon con todos estos nuevos procesos tecnológicos, políticos, sociales y económicos. Se desenvolvió un territorio de conexiones densas no exenta de una persistente tensión.

Aún en un entramado de relaciones colonialistas o asimétricas, surgieron espacios y capacidades para expresar agencias, de acciones con posibilidades que son compartidas (Ema 2004). Esto implicó la vinculación de la capacidad de acción con una concepción relacional del poder, dada por las determinaciones tomadas en el plano empresarial y político, decisiones que modificaron el devenir del altiplano y sus entornos. ${ }^{36}$ Por ello, hablar de capacidad y posibilidad tiene que ver con la potencia y el poder. Y entendemos esto como algo que circula en las relaciones (Foucault 1977) en un altiplano fronterizado y mercantilizado.

Hallamos, entonces, entre los empresarios y los indígenas, una "territorialización de potencia" (Deleuze y Guattari 2000) a movimientos que marcan territorios en tensión; por una parte, los empresarios que releen los códigos ancestrales, con vocación de orden y productividad, recurriendo/utilizando al indígena para los intereses de la compañía. Pero, por otro lado, los indígenas que constantemente manifiestan agenciamientos, al menos, en la circulación: fueron sus acciones una multiplicidad de posibilidades que comportaron términos heterogéneos y que establecieron uniones o relaciones. La propiedad única del agenciamiento es de cofuncionamiento: una simbiosis, una "simpatía" (Deleuze y Parnet 1997: 79).

Lo vivido en el sudoeste del altiplano boliviano, del enclave minero de Huanchaca, nos remite claramente a una especie de tensión entre el agenciamiento, que proyectó asociaciones diversas y heterogéneas, conectando símbolos, archivos culturales, y también posibilidades biográficas, materialidades, vialidades, paisajes, procesos sociales y políticos y, por sobre, todo de circulación. Parafraseando a Ema (2004), estos movimientos en tensión 
fueron la expresión de condiciones de posibilidad, algo más básico, primario, tangible y práctico, en la expresión de un encadenamiento de hechos y procesos, dando paso a una dinámica particular del altiplano una vez que se instauró la Compañía Minera Huanchaca.

En el decir de Schumpeter, todas estas fuerzas, en con- junto, son la causa primogénita del "proceso de mutación industrial que revoluciona incesantemente la estructura económica desde dentro, destruyendo interrumpidamente lo antiguo y creando continuamente elementos nuevos. Este proceso de destrucción creadora constituye el dato de hecho esencial del capitalismo" (Schumpeter 1978: 120).

\section{* Referencias citadas}

(DGEEG) Dirección General de Estadística y Estudio Geográfico de Bolivia. 1912. Boletín anual. La Paz.

ECHB. 1873. Estatutos de la Sociedad Compañía Huanchaca de Bolivia. Imprenta de la Patria, Valparaíso.

MDIAJH. 1876. Memoria del directorio e informe de la administración jeneral de Huanchaca. Imprenta del Mercurio de Tornero y Letelier, Valparaíso.

ABECIA, V. 1988. Mitayos de Potosí. Técnicos Editoriales Asociados, S.A., Barcelona.

AHUMADA, M. 1999. El establecimiento industrial de Playa Blanca en Antofagasta. Ediciones Universidad José Santos Ossa, Antofagasta.

ALMARAZ, S. 2009. Obra completa. Plural editores, La Paz.

ANTEZANA, L. 1985. Historia secreta del movimiento nacionalista revolucionario (1939-1943). Librería Editorial “Juventud”, La Paz.

ARCE, I. 1930. Narraciones Históricas de Antofagasta. Imprenta Moderna, Antofagasta.

ARDENTI, V. y R. PHILIPPE. 1999. Relations interentreprises et rapports de domination. Innovations: cahiers d'économie de l'innovation 9: 51-73.

ARDILES, H. 2010. Antofagasta catalizador del desarrollo regional. En Región de Antofagasta. Pasado, presente y futuro, A. Llagostera (Ed.), pp. 109-123. Universidad Católica del Norte, Antofagasta.

BARROS, A. 2008. Identidades y propiedad: Transiciones territoriales en el s. XIX atacameño. Estudios Atacameños 35: 119-139.

BARTOLOMÉ, A. 2008. Fronteras estatales y fronteras étnicas en América Latina. Notas sobre el espacio, la temporalidad y el pensamiento de la diferencia. En Migración, fronteras e identidades étnicas transnacionales, M. L. Velasco (Ed.), pp. 35-77. COLEF, Ti- juana, Miguel Ángel Porrúa, México, D. F.

BECK, U. 2008. ¿Qué es la globalización? Falacias del globalismo, respuestas a la globalización. Paidós, Barcelona.

BELLESSORT, A. 1897. Joven América: Chile y Bolivia. Versión original francesa. Perrin et Cie., París.

BENEDETTI, A. y E. SALIZZI. 2011. Llegar, pasar, regresar a la frontera. Aproximación al sistema de movilidad argentino-boliviano. Revista Transporte y Territorio 4: 148-179.

BOBILLER, E. 1897. La Compañía Huanchaca de Bolivia. Anales del Instituto de Ingenieros, tomo XII. [S.1.] Valparaíso.

CADEMARTORI, J. 2010. El desarrollo económico y social de la Región de Antofagasta. Ediciones Ordhum, Departamento de Economía, Facultad de Economía y Administración UCN, Antofagasta.

CHUNGARA, V. s/f. Tradiciones y leyendas de Uyuni. Ediciones Leonardo. Uyuni.

CONCHA y TORO, E. 1872. Informe relativo a la empresa Huanchaca basado sobre datos del ingeniero Luis Eich, sobre los planos de los ingenieros Vitriarius y Hugo Reky sobre las propias observaciones de Concha y Toro. Imprenta del Mercurio de Tornero y Letelier, Valparaíso.

CONNING, J. y J. ROBINSON. 2009. Enclaves and Development: An Empirical Assessment. Studies in Comparative International Development 44 (4):359-385.

DE MATTOS, C. 1984. El proceso de Concentración Territorial: ¿un obstáculo para el desarrollo?. Revista Interamericana de Planificación XVIII (70): 62-82.

DELEUZE, G. y C. PARNET. 1997. Diálogos. Pre-textos, Valencia.

DELEUZE, G. y F. GUATTARI. 2000. Mil mesetas. Capitalismo y esquizofrenia. Pre-textos, Valencia. 
DELGADO, M. 2007. Sociedades movedizas. Pasos hacia una antropología de las calles. Anagrama, Barcelona.

DEUSTUA, J. 2004. La minería en las Américas en el siglo XIX. El desarrollo de economías sociales. Historias. Revista del Instituto Nacional de Antropología e Historia 58: 83-95.

EMA, J. 2004. Del sujeto a la agencia (a través de lo político). Athenea Digital 6: 1-24.

ESCOBAR, F. 1984. Testimonio de un militante obrero. Instituto de Historia Social Boliviana, La Paz.

ESPINOZA, J. 2010. Minería Boliviana: su realidad. Plural editores, La Paz.

ESPINOZA, O. 1958. La postguerra del Pacífico y la Puna de Atacama (1884-1899). Editorial Andrés Bello, Santiago de Chile.

FERRER, A. 1975. La economía argentina. Las etapas de su desarrollo y problemas actuales. Fondo de Cultura Económica, Buenos Aires.

FINN, J. 1998. Tracing the veins: Of copper, culture and community from Butte to Chuquicamata. California University Press, Berkeley.

FOUCAULT, M. 1977. Historia de la Sexualidad. La voluntad de saber. Siglo XXI, México, D. F.

1996. Vigilary castigar. Siglo XXI, México, D. F.

2000. Defender la Sociedad: Curso en el Collège de France (1975-1976), H. Pons (Trad.). Fondo de Cultura Económica de Argentina S. A. Buenos Aires.

GALAZ-MANDAKOVIC, D. 2013. Migración y Biopolítica. Dos escenas del siglo XX tocopillano. Retruécanos Ediciones. Tocopilla.

GARCÉS, A. 2014. Contra el espacio público: criminalización e higienización en la migración peruana en Santiago de Chile. EURE 40: 141-162.

GARCÍA LINERA, A. 2000. Los ciclos históricos de la formación de la condición obrera minera en Bolivia (1825-1999). Revista Umbrales 7: 65-82.

GEPyFS (Grupo de Estudios Sobre Policías y Fuerzas de Seguridad CAS-IDES). 2012. Seguridad para todos. Territorios y policiamientos. Voces en el Fénix 15: 46-51.

GIDDENS, A. 1986. The constitution of society. Polity Press, Cambridge.

GÓMEZ, D. 2010. Conformación de la nortinidad regional. El componente étnico originario. En Región de Antofagasta. Pasado, presente y futuro, A. Llagostera (Ed.), pp. 222-237. Universidad Católica del Norte, Antofagasta.

GONZALEZ MIRANDA, S. 2009. La presencia boliviana en la sociedad del salitre y la nueva definición de la frontera: auge y caída de una dinámica transfronteriza (Tarapacá 1880-1930). Chungara. Revista de antropología chilena 41 (1): 71-81.

GONZÁLEZ PIZARRO, J. 2008. La emigración boliviana en la precordillera de la región de Antofagasta, 1910-1930. Redes sociales y estudios de casos. Revista Ciencias Sociales 21: 61-85.

2012. El vicario Luis Silva Lezaeta y el proceso de "chilenización" en el norte grande: las experiencias de Antofagasta y Tarapacá. 1882-1897. Revista Tiempo Histórico 5: 55-69.

GOTTMANN, J. 1973. The Significance of Territory. University of Virginia Press, Charlottesville.

HEVILLA, M. C. 1998. El estudio de la frontera en América. Una aproximación bibliográfica. Biblio $3 W$. Revista Bibliográfica de Geografía y Ciencias Sociales 125. En línea, disponible en: http://www. ub.edu/geocrit/b3w-125.htm

INSTITUTO GEOGRÁFICO ARGENTINO. 1894. Boletín anual. Buenos Aires.

LANGER, E. y V. CONTI. 1991. Circuitos comerciales tradicionales y cambio económico en los Andes Centromeridionales (18301930). Desarrollo Económico 31 (121): 91-111.

LAZARTE, J. 1987. Movimiento obrero y procesos politicos en Bolivia. Historia de la COB, 1952-1987. Instituto Latinoamericano de Investigaciones Sociales (ILDIS), La Paz.

LEVIN, J. 1960. The export economies: their pattern of development in historical perspective. Harvard University Press, Cambridge, Mass.

LEVY, J. 2000. Les Nouveaux Espaces de la Mobilité. En Les Territoires de la Mobilité, M. Bonnet y D. Desjeux (Eds.), pp. 155-170. Presses Universitaires de France, París.

LÓPEZ, V. 2011. Uyuni: Historia de un pasado glorioso. Editorial Adonai, Cochabamba.

MACHADO, L. 2000. Limites e fronteiras: Da alta diplomacia aos circuitos da ilegalidade. Revista Territorio 8: 9-29.

MAMANÍ, N. s/f. Reseña histórica Mina Pirquitas. En línea, disponible en: http://www.enernews.com/media/briefs/MPI historia 152.pdf (Consultado 3 de marzo 2016). 
MARINKOVIC, V. 2011. Uyuni: ¿un nuevo campamento emergente? Revista Energía Bolivia. En línea, disponible en: http://webcache.googleusercontent.com/ search?q=cache: 1 bNTWKIU2oEJ:www.energiabolivia.com/ index.php\%3Foption\%3Dcom_content\%26view\%3 Darticle \%26id\%3D 612\%26Itemid\%3D105+\&cd = 1 \&hl =es-419\&ct $=\mathrm{cl}$ $\mathrm{nk} \& \mathrm{gl}=\mathrm{cl}$

MESA, C., J. MESA y T. GISBERT. 2007. Historia de Bolivia. Editorial Gisbert, La Paz.

MITCHELL, D. 2003. The right to the city. Social justice and the fight for public space. Guilford Press, Nueva York.

MITRE, A. 1981. Los patriarcas de la plata: Estructura socioeconómica de la minería boliviana en el siglo XIX. Instituto de Estudios Peruanos, Lima.

MONTERO, R. 2004. Caravaneros y trashumantes en los Andes meridionales: población y familia indígena en la puna de Jujuy, 1770-1870. Instituto de Estudios Peruanos, Lima.

MORALES, I. 2010. El aporte de los inmigrantes extranjeros. En Región de Antofagasta. Pasado, presente y futuro, A. Llagostera (Ed.), pp. 204-221. Universidad Católica del Norte, Antofagasta.

NEWMAN, D. 2006. The lines that continue to separate us: borders in our "borderless" world. Progress in Human Geography 30 (2): 143-161.

PLATT, T. 1987. Calendarios tributarios e intervención mercantil. Racionalidades estacionales entre los indios de Lípez (Bolivia) en el Siglo XIX. Chungara 19: 215-241.

2014. Caccheo y minería mediana en las Provincias de Potosí: Lípez Y Porco (1830-1850). Estudios atacameños 48: 85-118.

PRIES, L. 2002. Migración transnacional y la perforación de los contenedores de Estados- nación. Estudios Demográficos y Urbanos 17: 517-597.

QUEREJAZU, R. 1996. Uyuni: Hija predilecta de Bolivia. Autoedición, Uyuni.

RACZYNSKI, D., R. CORTÁZAR, P. MELLER, A. HIRSCHMAN y A. PINTO. 1983. Estrategias de Desarrollo y Economía. Colección Estudios, $\mathrm{N}^{\circ} 10$, CIEPLAN. En línea, disponible en: http:// www.cieplan.org/biblioteca/detalle.tpl?id=122

RECABARREN, F. 2002. Episodios de la vida regional. Ediciones universitarias, Universidad Católica del Norte, Antofagasta.

RISOPATRÓN, L. 1910. La línea de frontera con la República de Bolivia. Sociedad Imprenta y Litografía Universo, Santiago de Chile.
RODRIGUEZ, G. 2014. Capitalismo, modernización y resistencia popular, 1825-1952. Vicepresidencia del Estado Plurinacional, Centro de Investigaciones Sociales, La Paz.

RUTLEDGE, I. 1987. Cambio agrario e integración: el desarrollo del capitalismo en Jujuy, 1550-1960. Proyecto ECIRA, Tilcara, Jujuy, Centro de Investigaciones en Ciencias Sociales, Buenos Aires.

SALAZAR, F. 2006. Bolivia y Chile: desatando nudos. Plural Editores, La Paz.

SANHUEZA, C. 2001. La población de la puna de Atacama y su relación con los Estados Nacionales. Una lectura desde el archivo. Revista de Historia Indígena 5: 55-82.

2012. La tradición arriera de Atacama (siglo XIX). En Atacama, C. Aldunate (Ed.), pp. 236-257. Museo Chileno de Arte Precolombino, Santiago de Chile.

SCHUMPETER, J. 1978. Teoría del desenvolvimiento económico. Fondo de Cultura Económica, México, D. F.

SERRANO, C. 2004. Historia de la minería andina boliviana (Siglos XVI-XX). UNESCO, Potosí.

SISSON, W. 1905. Informe del Reconocimiento sobre el proyectado Sistema de Ferrocarriles Bolivianos. Impr. Heitmann y Cornejo, La Paz.

SUBIETA, L. 1928. Potosí antiguo y moderno. Tip. Minerva, Potosí.

VAN DER VELDE, M. y T. VAN NAERSSEN. 2010. People, borders, trajectories: an approach to cross-border mobility and immobility in and to the European Union. Area 43 (2): 218-224.

VELAZQUEZ, J. 1905. La Compañía Huanchaca de Bolivia. Boletín de Minas, Industria y Construcciones 1 (1): 9-11.

WRIGH, M. 1907. Bolivia, el camino central de Sur-América, una tierra de ricos recursos y de variado interés. Editor Jorge Barrie, Filadelfia.

ZAVALETA, R. 1983. Bolivia hoy. Siglo XXI Editores, México D. F.

\section{Archivos}

AMU: Archivo Municipal de Uyuni.

AGOB: Archivo Gaceta Oficial de Bolivia.

AJA: Archivo Judicial de Antofagasta.

AERCIAB: Archivo de Extranjería del Registro Civil e Identificaciones de Antofagasta, Bolivia. Perteneciente al Archivo histórico UCN, Antofagasta. 